\title{
Experimental settling, floatation and compaction of plagioclase in basaltic melt and a revision of melt density
}

\author{
Giuliano Krättli ${ }^{1}$ (D) Max W. Schmidt ${ }^{1}$
}

Received: 13 March 2020 / Accepted: 28 February 2021

(c) The Author(s) 2021

\begin{abstract}
Centrifuge-assisted piston cylinder experiments were conducted on plagioclase in basaltic melt at $1140-1250{ }^{\circ} \mathrm{C}, 0.42-0.84$ $\mathrm{GPa}$ and mostly $1000 \mathrm{~g}$. One set of experiments assesses the settling velocity of a dilute plagioclase suspension; a second sinks or floats plagioclase in a MORB-type melt exploring conditions of neutral buoyancy; and a third set examines floatation of plagioclase from an evolved lunar magma ocean composition. A compaction rate for plagioclase cumulates is established. The experiments demonstrate that neutral density of plagioclase $\mathrm{An}_{74}$ in a MOR-type tholeiitic basalt occurs at $0.59 \pm 0.04 \mathrm{GPa}\left(1200^{\circ} \mathrm{C}\right)$, contrasting predictions by present models on melt density which yield a density inversion pressure at $0.10-0.15 \mathrm{GPa}$. In nature, the level of neutral buoyancy depends on melt composition; nevertheless, for the onset of plagioclase crystallization in dry tholeiitic basalts, our result is robust. As the molar volume of plagioclase is well known, the experimentally determined pressure of neutral buoyancy indicates a correction of $-1.6 \%$ to previous density models for silicate melts. It follows that for (tholeiitic) layered mafic intrusions, plagioclase is negatively buoyant for early, relatively primitive, parent melts. In contrast, the extreme Fe enrichment of a fractionating lunar magma ocean leads to melt densities that let anorthite always float. Compaction $\varphi / \varphi_{0}$ of experimental plagioclase cumulates is quantified to $\varphi / \varphi_{0}=-0.0582 \log$ $(\Delta \rho \cdot h \cdot a \cdot t)+1.284$, where $\varphi_{0}$ is the porosity after settling $(67 \pm 2 \%), h$ the cumulate pile height, $a$ acceleration and $\varphi$ porosity as a function of time $t$. Gravitational-driven compaction in tens of $m$-thick plagioclase cumulate in basaltic magmas reaches down to $\sim 40 \%$ porosity within hundreds of years, a timescales competing with characteristic cooling times of cumulate layers of mafic intrusions. To achieve plagioclase modes $>80 \%$ due to compaction, an additional overload of $\sim 100 \mathrm{~m}$ (layers) of mafic minerals would be required. Compaction of a lunar anorthosite crust of $35 \mathrm{~km}$ to $20 \%$ porosity (i.e. 90\% plagioclase after crystallization of the interstitial melt) would require 30 kyrs.
\end{abstract}

Keywords Anorthosite $\cdot$ Plagioclase $\cdot$ Neutral buoyancy $\cdot$ Layered mafic intrusion $\cdot$ Moon $\cdot$ Centrifugation

\section{Introduction}

Cumulate rocks are archives of fractional crystallization processes in magmatic systems; in fact, intrusive rocks derived from basaltic melts such as gabbros, troctolites and norites are generally cumulative and do not represent true melt compositions (e.g. Bowen 1917; Irvine 1969, 1982; Jagoutz et al. 2011). With this respect, anorthosites are an extreme as they reach $\geq 90 \%$ plagioclase, while their parental melts typically

Communicated by Timothy L. Grove.

Giuliano Krättli

giuliano.kraettli@gmail.com

1 Institute of Geochemistry and Petrology, ETH Zürich, 8092 Zürich, Switzerland have $\leq 50 \%$ normative plagioclase. This study investigates plagioclase cumulate formation experimentally in order to understand whether gravitation and density differences may provide enough driving force for anorthosites formation as proposed by Kushiro and Fujii (1977).

Plagioclase-rich cumulates are common in shallow magma systems such as mid-ocean ridges, large igneous provinces, layered mafic intrusions (LMI) and are an important constituent of the primordial lunar crust. Most anorthosites may be allocated to three eras: primordial anorthosites, Archean megacrystic anorthosites and Proterozoic massif-type anorthosites (Ashwal and Bybee 2017). Three more groups with little temporal connotation are anorthosites of layered mafic intrusions, of oceanic crust and those found as enclaves (Ashwal 1993). Primordial anorthosites are likely related to planet-scale fractionation 
and differentiation of magma oceans. Archean megacrystic anorthosites are thought to derive in an environment with a hot mantle and a thin crust, whereas massive-type anorthosites require a thicker crust (Ashwal and Bybee 2017). All these processes involve gravitational accumulation and hence physical fractionation of plagioclase from a largely tholeiitic parent liquid.

Stokes settling (Stokes 1851) provides the basis to describe the segregation of individual plagioclase crystals from melt. The nonspherical shape and the interaction between plagioclase crystals lead to more complex movements including, for example, rotational, rafting and/ or wake effects (Joseph et al. 1986; Schwindinger 1999). Furthermore, dense suspensions undergo hindered settling (Faroughi and Huber 2015; Richardson and Zaki 1954; Tomkins et al. 2005), such that the effective settling velocity of a mineral suspension needs to be determined experimentally, which is one of the aims of this study.

Once settled, grain rotation and particle size sorting at the interface with the melt and within the cumulate contribute to the final packing density of an orthocumulate (Wager et al. 1960), defined as to form only through physical means, grains building an interconnected grid from sedimentation only. Further compaction then involves chemical dissolution and precipitation driven by the density differences between crystals and magmatic liquid (Khazan 2010; McKenzie 1987; Schmidt et al. 2012), by thermal gradients (thermophoresis and Soret effects: Lesher and Walker 1988; Soret 1880), by particle size equilibration (Ostwald ripening: Cabane et al. 2005; Faul and Scott 2006; Ostwald 1900) and also by the unavoidable changes in intrinsic variables such as temperature, pressure or melt composition.

Some pioneering experimental studies on plagioclase settling in silicate melt exist (Campbell et al. 1978; Kadik and Lebedev 1995; Roeder and Dixon 1977; Walker and Hays 1977). These were, however, run in open systems at 1 atm and were hampered by oxidation (causing magnetite formation) and bubble formation. To decipher and quantify the processes that control the formation of gravitational plagioclase cumulates from basaltic melts, we use the centrifuging piston cylinder (Schmidt et al. 2006), successfully employed for settling and compaction of olivine and chromite in basaltic liquids (Manoochehri and Schmidt 2014; Schmidt et al. 2012). One of our aims is to understand whether plagioclase moves noticeably differently from rather isometric olivine and chromite crystals. In the initial phase of this study, we observed settling, neutral buoyancy and floating of plagioclase in a mafic melt at pressures different from those predicted from Lange and Carmichael (1990) melt volumes, leading to a correction of melt density. Secondly, we targeted compaction of plagioclase cumulates, although the small density differences of anorthite-rich plagioclase and MORtype mafic melts render experimental compaction difficult.
We hence also used a dense, Fe-rich evolved lunar magma ocean composition, also testing the widely accepted hypothesis that plagioclase floatation (Smith et al. 1970) resulted in the primordial crust of the Moon. Finally, we evaluate which layered mafic intrusions would have early plagioclase sinking and which ones floating.

\section{Experimental and analytical technique}

Three sets of experiments were designed to quantify the settling velocity and compaction rates of plagioclase cumulates. For the settling experiments, a relatively dilute 9:1 melt/ plagioclase mixture (in wt\%) was used to obtain long settling distances inside the capsule. In all other experiments, a melt/plagioclase ratio of 7:3 was used to generate a cumulate pile of maximum height, hence amplifying compaction. In the second set of experiments, pressure was varied to determine the conditions of density inversion (or neutral buoyancy). While the first two sets were conducted on a MOR-type basaltic melt, the third set employed an Fe-rich (lunar) melt representing the onset of plagioclase crystallization at a fairly evolved stage of a tholeiitic liquid line of descent (LLD).

\section{Starting materials}

Starting materials were composed of synthetic mixtures with compositions appropriate of tholeiitic melts (stg3 and twm9, Table 1) mixed with natural plagioclase seeds with $77 \mathrm{~mol} \%$ anorthite $\left(\mathrm{An}_{77}\right)$ and a well-sieved grain size. Since intracrystalline diffusion in plagioclase is too slow to significantly progress on experimental timescales (Aigner-Torres et al. 2007; Grove et al. 1984), we selected a plagioclase composition close to equilibrium with the basaltic melt. Initial pilot experiments showed that plagioclase compositions with an $X_{\mathrm{An}}$ lower than equilibrium led to extensive dissolution (Appendix II), while plagioclase with $X_{\mathrm{An}}$ values higher than equilibrium yielded growth rims. This behavior can be rationalized by considering that anorthite contents higher than the equilibrium value require dissolution temperatures higher than the experimental value, while the opposite is true for lower seed anorthite contents. Crystals in which cores dissolve eventually collapse, rendering meaningful geometrical analyses of compaction difficult.

The MOR-type basaltic composition (stg3, Table 1) was chosen from an experimental fractionation series by Villiger et al. (2007) and represents their starting composition 7Fr4 of experiment SV99, crystallizing a large amount of plagioclase of $\mathrm{An}_{71}$ at its liquidus at $1210{ }^{\circ} \mathrm{C}(0.7 \mathrm{GPa})$. The third set of experiments was conducted on a melt composition (twm9, Table 1) obtained from our ongoing study on fractional crystallization of the lunar magma ocean and is 
Table 1 Starting melt, plagioclase and mixture compositions

\begin{tabular}{|c|c|c|c|c|c|c|c|}
\hline \multirow[t]{3}{*}{$\mathrm{wt} \%$} & \multicolumn{4}{|c|}{ Melt and plagioclase compositions } & \multicolumn{3}{|c|}{ Starting mixes } \\
\hline & \multirow[t]{2}{*}{$\operatorname{stg} 3$} & \multirow[t]{2}{*}{ twm9 } & \multirow[t]{2}{*}{ plag* } & \multirow{2}{*}{$\begin{array}{l}\text { stdv } \\
1 \sigma\end{array}$} & \multicolumn{2}{|c|}{ stg $3+$ plag } & \multirow{2}{*}{$\begin{array}{l}\text { twm9+plag } \\
(70: 30)\end{array}$} \\
\hline & & & & & $(90: 10)$ & $(70: 30)$ & \\
\hline $\mathrm{SiO}_{2}$ & 52.3 & 42.9 & 48.9 & 0.71 & 52.0 & 51.3 & 44.8 \\
\hline $\mathrm{TiO}_{2}$ & 1.00 & 3.97 & 0.11 & 0.03 & 0.91 & 0.73 & 2.82 \\
\hline $\mathrm{Al}_{2} \mathrm{O}_{3}$ & 16.0 & 10.5 & 32.7 & 0.54 & 17.7 & 21.0 & 17.2 \\
\hline $\mathrm{FeO}$ & 9.85 & 25.7 & 0.26 & 0.03 & 8.89 & 6.97 & 18.1 \\
\hline $\mathrm{MnO}$ & - & 0.75 & bdl & - & - & - & 0.52 \\
\hline $\mathrm{MgO}$ & 7.26 & 4.55 & 0.02 & 0.01 & 6.54 & 5.09 & 3.19 \\
\hline $\mathrm{CaO}$ & 10.3 & 10.1 & 15.4 & 0.43 & 10.8 & 11.9 & 11.7 \\
\hline $\mathrm{Na}_{2} \mathrm{O}$ & 2.92 & 1.07 & 2.60 & 0.22 & 2.89 & 2.82 & 1.53 \\
\hline $\mathrm{K}_{2} \mathrm{O}$ & 0.32 & 0.15 & bdl & - & 0.29 & 0.23 & 0.12 \\
\hline Total & 100.0 & 100.0 & 100.0 & & 100.0 & 100.0 & 100.0 \\
\hline Norm. plag. mode (wt $\%$ ) & 42 & 24 & - & & 46 & 55 & 42 \\
\hline$X_{\mathrm{An}}(\mathrm{Ca} /(\mathrm{Na}+\mathrm{Ca})$ molar $)$ & 0.66 & 0.84 & 0.77 & & 0.67 & $\mathbf{0 . 7 0}$ & 0.78 \\
\hline$X_{\mathrm{Mg}}(\mathrm{Mg} /(\mathrm{Mg}+\mathrm{Fe})$ molar $)$ & 0.57 & 0.24 & - & & 0.57 & 0.57 & 0.24 \\
\hline Viscosity at $1225^{\circ} \mathrm{C}(\mathrm{Pa} \cdot \mathrm{s})$ & 49 & 15 & - & & - & - & - \\
\hline
\end{tabular}

$b d l$ below detection limit

$*_{n}$ (number of analyses) $=29$ saturated in plagioclase of $\mathrm{An}_{74}$ at $1120{ }^{\circ} \mathrm{C}, 0.5 \mathrm{GPa}$. The melt compositions were prepared from high-purity oxides and synthetic silicates, i.e. $\mathrm{SiO}_{2}, \mathrm{TiO}_{2}, \mathrm{Al}_{2} \mathrm{O}_{3}$ and $\mathrm{MgO}$, fired at $1000{ }^{\circ} \mathrm{C}, \mathrm{Fe}_{2} \mathrm{SiO}_{4}, \mathrm{MnO}, \mathrm{CaSiO}_{3}, \mathrm{Na}_{2} \mathrm{SiO}_{3}$ and $\mathrm{KAlSi}_{2} \mathrm{O}_{6}$, dried overnight at $220{ }^{\circ} \mathrm{C}$. Fayalite was synthesized from fine-grained $(<10 \mu \mathrm{m}) \mathrm{SiO}_{2}$ and $\mathrm{Fe}_{2} \mathrm{O}_{3}$ in a one atmosphere oven at $1170{ }^{\circ} \mathrm{C}, \mathrm{QFM}-2$, for $24 \mathrm{~h}$, and the product was verified by X-ray diffraction. The components were weighed, mixed and milled to a fine $(<10 \mu \mathrm{m})$ homogeneous powder.

Plagioclase $\left(\mathrm{An}_{77}\right)$ was extracted from a Stillwater Complex sample (Corlett and Eberhard 1967) from the ETH rock collection. Plagioclase was handpicked from the crushed sample and then gently milled in an agate mortar and sieved under ethanol. Only the grain fraction between the 48 and $52 \mu \mathrm{m}$ sieves was used, yet, subsequent milling with the melt component may lead to some grain size reduction. Post-experiment grain sizes (uncorrected for 2D-3D effects) are measured to be $39 \pm 15 \mu \mathrm{m}(\mathrm{n}=58)$ for the first set and $29 \pm 19(n=4168)$ for the second set. As these postexperiment plagioclases have micron-thick growth rims, we assume that the true starting grain size of plagioclase is near the average of the observed post-experiment grain size.

\section{Piston cylinder experiments}

To simulate gravitational cumulate formation, we combined static and centrifuging piston cylinder experiments. In both setups, pressure vessels are very different in size but have an identical 14-mm-diameter bore and hence identical $14 \mathrm{~mm}$ assemblies of talc and pyrex sleeves surrounding straight graphite furnaces. The welded capsule was placed into inner crushable $\mathrm{MgO}$ parts. A thin corundum disk separates the B-type $\mathrm{Pt}_{94} \mathrm{Rh}_{6}-\mathrm{Pt}_{70} \mathrm{Rh}_{30}$ thermocouple from the capsule to avoid contamination. The hot spot for this setup was modeled according to Hernlund et al. (2006) and confirmed experimentally following Watson et al. (2002), both methods yielding a temperature gradient across the sample chamber of $<5^{\circ} \mathrm{C}$ (at $1200{ }^{\circ} \mathrm{C}$ ). The sample was placed inside an iridium capsule (fabricated by electro-erosion of a rod) and a tightly inserted lid yielding a 4-mm-long sample chamber with $3 \mathrm{~mm}$ diameter $(6 \mathrm{~mm}$ total capsule length and $4 \mathrm{~mm}$ o.d.).

Iridium was used because its chemical inertness results in little Fe loss and because it perfectly conserves the cylindrical geometry with smooth capsule walls, as required to quantify crystal settling and compaction. In a dry system, oxygen fugacity cannot be buffered by conventional double capsule methods. To approach relatively reducing conditions as characteristic for the early stages of tholeiitic magma evolution, synthetic fayalite was used as the only $\mathrm{Fe}$ source. Minor Fe loss (0-12\% relative of total $\mathrm{FeO}$, Table 2) to the capsule wall results in some oxidation of the sample, allowing to calculate $\mathrm{fO}_{2}$ (see below).

All centrifuged experiments were first equilibrated for $48 \mathrm{~h}$ in a static endloaded piston cylinder, quenched and the (unopened) capsule was recovered. The capsule was then reloaded in a fresh assembly into the centrifuging piston cylinder. The centrifuge has a 1.6-m-diameter rotating table with a $42 \mathrm{~kg}$ single-stage piston cylinder as payload (Schmidt et al. 2006), the sample sitting at a radial distance 


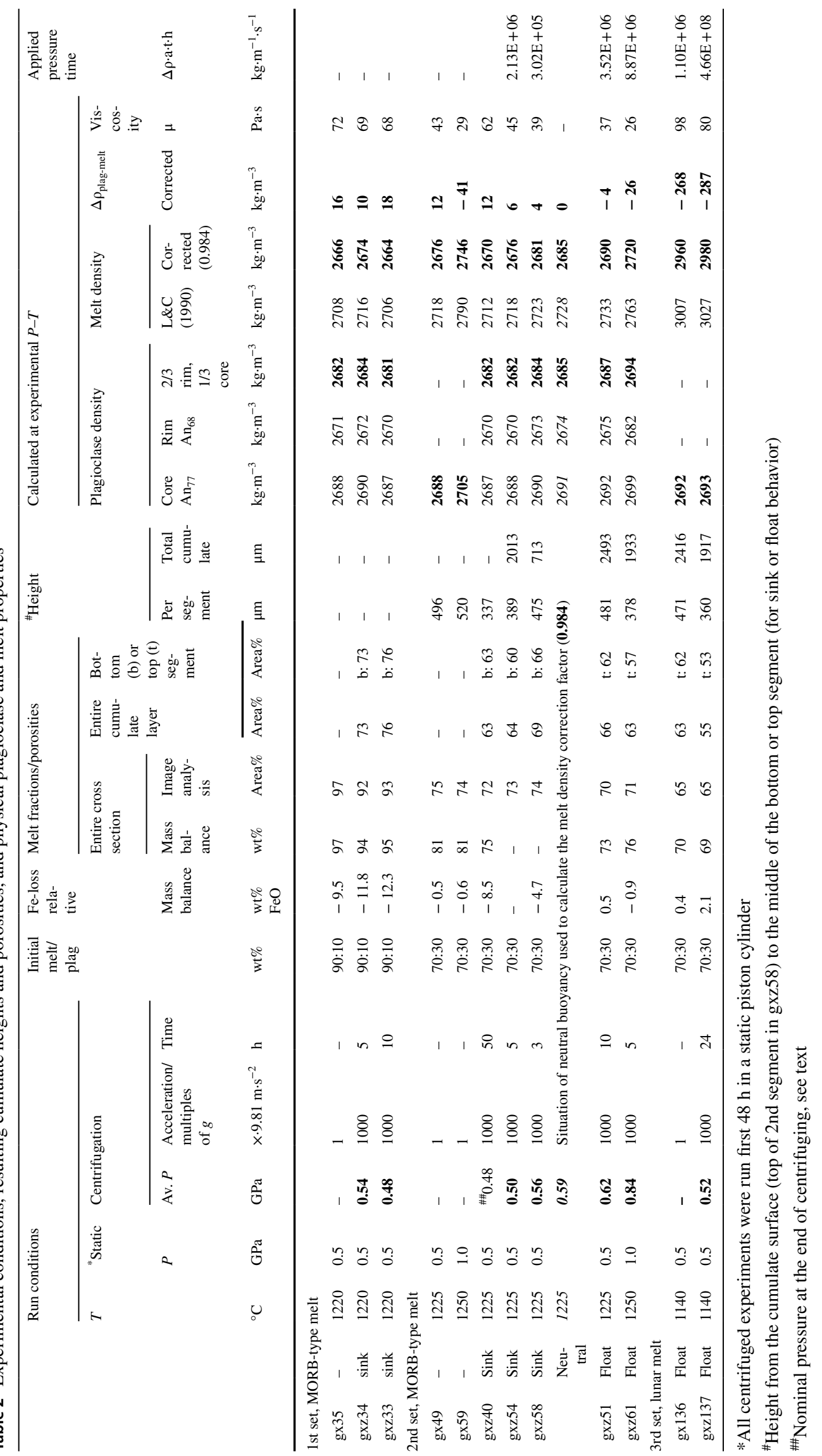


of $32 \mathrm{~cm}$ from the central axis. Heating through the slip ring stack requires rotation, in which minimum is $200 \mathrm{rpm}$ (yielding $15 \mathrm{~g}$ ). Because oil pressure is only measured but could not be adjusted during rotation, a first heating period of $20 \mathrm{~min}, 1000{ }^{\circ} \mathrm{C}$ (at $200 \mathrm{rpm}$ ) serves to soften the pyrex and to collapse most of the porosity in the assembly components. Then, after quenching, hydraulic oil pressure of the piston cylinder is adjusted, the centrifuge restarted and rotation increased to $1660 \mathrm{rpm}(1000 \mathrm{~g})$ while heating. Oil pressure then slightly decreases with time (corresponding to a piston-in procedure) such that nominal pressure decreases, in our experiments between -0.01 and $-0.05 \mathrm{GPa}$ except of gxz40 where centrifugation for $50 \mathrm{~h}$ led to a nominal pressure loss of $-0.26 \mathrm{GPa}$. All experimental parameters are automatically logged to quantify any drift. Experiments were quenched by switching off electrical power. The recovered capsules were mounted longitudinally in epoxy, ground and polished to their rotational axis, and finally carbon coated for further analysis.

The talc-pyrex- $\mathrm{MgO}$ assembly was calibrated against the quartz $=$ coesite transition at $1000{ }^{\circ} \mathrm{C}$ and $3.07 \mathrm{GPa}$ (Bose and Ganguly 1995) and the fayalite + quartz $=$ orthoferrosilite reaction at $1000{ }^{\circ} \mathrm{C}$ and $1.41 \mathrm{GPa}$ (Bohlen and Boettcher 1980) in the static piston cylinder and found to have $-10 \%$ friction correction. All experiments were run with a piston-in procedure. Oil pressure was held constant within 0.2 bar (equivalent to $0.0016 \mathrm{GPa}$ applied pressure) by an automated screw worm jack in the static experiments, a procedure that requires only forward movement of its piston. To ensure the validity of this friction correction at the relatively low pressures critical to this study, the assemblage was also calibrated against the melting curve of $\mathrm{NaF}$ (Clark 1959). NaF was chosen (i) because the twice higher $\mathrm{dT} / \mathrm{dP}$ slope of the $\mathrm{NaF}$ melting curve than, for example, $\mathrm{Au}(\sim 1.0$ vs $\sim 0.5^{\circ} \mathrm{C} / \mathrm{GPa}$ ) and (ii) because $\mathrm{NaF}$ has the highest melting temperature of all salts investigated by Clark (1959), i.e. the one closest to the experimental temperatures. For this purpose, $\mathrm{Au}_{80} \mathrm{Pd}_{20}$ capsules of $5.0 \mathrm{~mm} \mathrm{OD}$ and $7 \mathrm{~mm}$ length were loaded with $\mathrm{NaF}$ such that almost no porosity resulted: Capsules were repeatedly filled with $\mathrm{NaF}$ powder and each time placed in a box furnace at $1000{ }^{\circ} \mathrm{C}$, such that the $\mathrm{NaF}$ melted until the entire capsule was filled with a solid piece of $\mathrm{NaF}$. Melting in the piston cylinder was then detected by a depression in the measured temperature when heating with a constant power rate (corresponding to ca. $35^{\circ} \mathrm{C} / \mathrm{min}$ ). Six melting points at $0.3-0.6 \mathrm{GPa}$ were determined placing the capsule in the hot spot of the assemblage. All of them were found to lie within $0.02 \mathrm{GPa}$ of the pressure corrected by $-10 \%$ friction, with an average deviation of $0.010 \mathrm{GPa}$. To ensure pressure reproducibility, the $\mathrm{NaF}$ melting point was also reproduced twice in the centrifuge (at 0.37 and 0.43 $\mathrm{GPa}$ ), yielding the same friction correction. The $\mathrm{NaF}$ melting curve is given with a standard deviation of $1.3^{\circ} \mathrm{C}$ (Clark
1959) corresponding to $\pm 0.008 \mathrm{GPa}$. The temperature accuracy in the calibration experiments is about $5{ }^{\circ} \mathrm{C}\left(2-3{ }^{\circ} \mathrm{C}\right.$ on the instrumental temperature reading and $2-4{ }^{\circ} \mathrm{C}$ for the correction of the thermal gradient within the assemblage), such that pressure should be known to be $\pm 0.03 \mathrm{GPa}$ (at $0.3-0.6 \mathrm{GPa})$.

\section{Image analysis}

A JEOL JSM-6390LA scanning electron microscope was used for microstructural observations. Typically, 18 highresolution backscattered electron (BSE) mosaic images were acquired and assembled using a photomerge function. Images were cleaned from cracks and eventual quench crystals that would affect porosity or melt fraction analysis (Table 2, Figs. 1, 2, 3, 4). A rectangular area with $20 \%$ smaller than the capsule diameter or cumulate top-to-bottom distance was used for 2-D analysis (Figs. 2,3,4). This area was sliced into five horizontal segments yielding a porosity profile over the cumulate pile. Images were converted to binary plagioclase vs. melt using the threshold function of the ImageJ software (Schneider et al. 2012). Errors on the counting scheme are difficult to estimate since the binary pixel count is exact. One sample was ground further down by $10 \mu \mathrm{m}$, repolished, and the image analysis was repeated (Appendix II), yielding a difference of $<1$ area\% between the first and second analyses. No 2D-3D conversion was applied due to the complex shapes of the plagioclase grains. Mass balance calculations yield bulk melt fractions (Table 2) a few percent lower than the overall porosity from image analysis. This difference remains within error (a few $\%$ for each method) but is probably also a result of a somewhat uneven distribution of melt-rich areas.

\section{Chemical analysis}

Plagioclase and melt compositions were measured employing a JEOL JXA-8200 electron microprobe with five wavelength-dispersive $\mathrm{X}$-ray spectrometers (WDS). The electron beam had $15 \mathrm{kV}$ and 20 or $8 \mathrm{nA}$ and a beam diameter of 10 or $20 \mu \mathrm{m}$ for melt or plagioclase analysis, respectively. A combination of natural and synthetic silicates and oxides as used as standards for calibration. Counting times were $20 \mathrm{~s}$ (excepting $\mathrm{Na} 10 \mathrm{~s}$ ) on the peak and $10 \mathrm{~s}$ (for $\mathrm{Na} 5 \mathrm{~s}$ ) on each background.

\section{Experimental results}

A summary of run conditions, measured porosities and calculated mineral and melt densities for all three series is given in Table 2 and illustrated in Figs. 1, 2, 3, 4. The capsules rotational axes are horizontal during centrifugation (vertical 
(a)

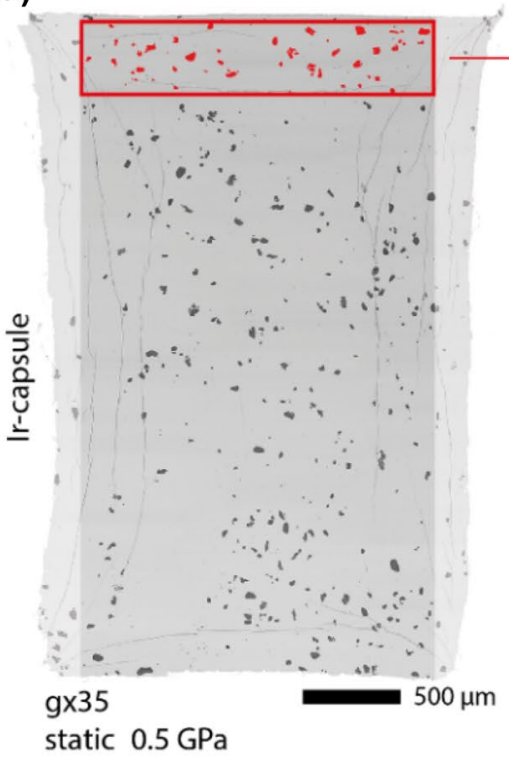

$\Delta \rho_{\text {plag-mett(corr.): }} 16\left(\mathrm{~kg} \cdot \mathrm{m}^{-3}\right)$ (b)

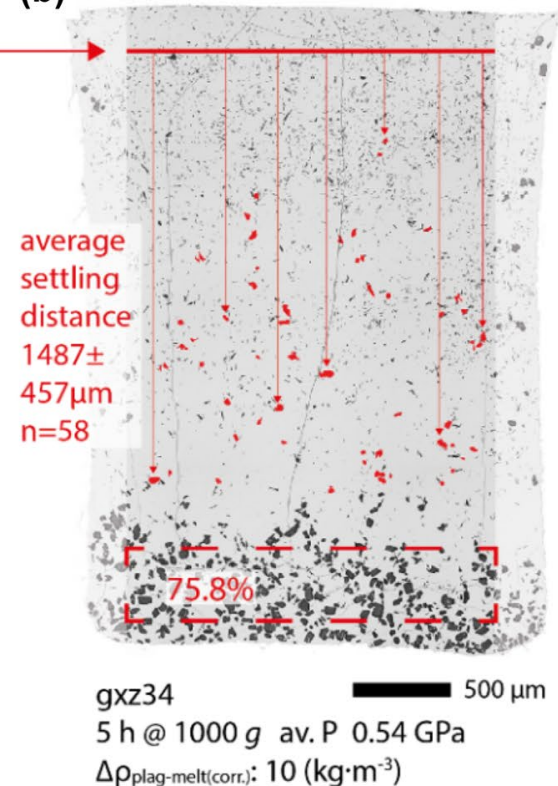

(c)

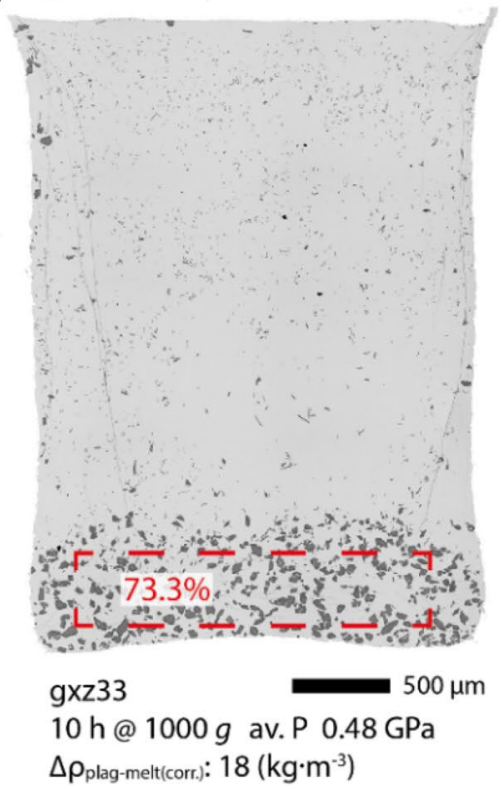

Fig. 1 BSE images of the 9:1 melt/plag (initial weight proportion) settling experiments performed at $0.5 \mathrm{GPa}, 1220{ }^{\circ} \mathrm{C}$ in Ir-capsules (white, in Figs. 1, 2, 3 only the inner rim of the Ir container is shown), the light-gray area depicts the border zone excluded from analysis. The labels in the lower boxes give porosity or melt percent-

in static experiments), yet, throughout the text, bottom and top or floating and sinking refer to the direction of maximum acceleration. All images of the experimental charges are oriented with the maximum acceleration pointing to the bottom.

\section{Run products}

For each series, one or two experiments were run without centrifugation for $48 \mathrm{~h}$ at static conditions in order to define the initial crystal distribution (Figs. 1a, 2a, h, 3a). Furthermore, gx35 was run statically through all heating and quenching steps as when centrifuging, i.e. $48 \mathrm{~h}$ of equilibration, quenching, $20 \mathrm{~min}$ at $1000{ }^{\circ} \mathrm{C}$, quenching, and finally $3 \mathrm{~h}$ at $0.5 \mathrm{GPa}, 1220^{\circ} \mathrm{C}$ (representing the period otherwise used for centrifugation). The result being no different from the other static experiments, subsequent static experiments were simply held for $48 \mathrm{~h}$ at run condition (Table 2). For the MOR-type basalt, homogeneous crystal distributions resulted. For the lunar melt composition, a thin crystal-free zone is already present at the bottom of the experimental charge (gx136, Fig. 3a).

Plagioclase grains are equigranular to slightly elongate with mean sizes of $39 \pm 14 \mu \mathrm{m}$ (long axis) and $21 \pm 7 \mu \mathrm{m}$ (short axis, experiment gxz34). These values vary slightly with starting material batches. ages. a Static. b Centrifuged for $5 \mathrm{~h}$ at $1000 \mathrm{~g}$, most but not all grains settled to the bottom. c Centrifuged for $10 \mathrm{~h}$ at $1000 \mathrm{~g}$, all grains except some "late-comers" (see text) have settled to the bottom. The red grains in figures $\mathbf{a}$ and $\mathbf{b}$ approximate the distance of settling due to gravitational acceleration

The melts of all experiments quenched to homogeneous glasses, whose compositions (Table 3) correspond to the starting composition (Table 1) except for $0.0-12.3 \mathrm{wt} \%$ relative Fe loss (Table 2) and/or some dissolution of plagioclase seeds. The latter yields somewhat higher $\mathrm{Al}_{2} \mathrm{O}_{3}$ and $\mathrm{CaO}$ and lower $\mathrm{FeO}$ and $\mathrm{MgO}$ concentrations in the experimental melts (Table 3).

Fe loss to the capsule results in a net oxidation of the melt according to $3 \mathrm{Fe}^{2+}=\mathrm{Fe}_{\text {capsule }}^{0}+2 \mathrm{Fe}^{3+}$. Fe-loss was determined mass balancing the other major oxides for measured melt and plagioclase compositions vs. the starting material (Table 2) and balancing the melt mode and $\mathrm{FeO}$ concentration vs. the starting $\mathrm{FeO}$ content. For the settling experiments, the Fe loss was $9.5-12.3 \%$ relative to total $\mathrm{FeO}$, on average $11.2 \%$, which yields an $\mathrm{Fe}^{3+} / \mathrm{Fe}^{\text {tot }}{ }_{\text {melt }}=0.25$ corresponding to a (logarithmic) oxygen fugacity of $\triangle \mathrm{QFM}+1.9$ (Kress and Carmichael, 1991). For the float/sink and compaction experiments, the average $\mathrm{Fe}$ loss was $2.3 \%$ relative, yielding a melt $\mathrm{Fe}^{3+} / \mathrm{Fe}^{\text {tot }}=0.047$ and an oxygen fugacity of $\Delta \mathrm{QFM}-1.8$. Note that Fe losses in the lunar melt composition with $25.7 \mathrm{wt} \% \mathrm{FeO}$ were $0.4-2.1 \%$ relative, demonstrating the perfect suitability of Ir as capsule material for this type of experiments.

The average composition of 117 EPMA analyses of plagioclase cores (Table 3 ) from various experiments is equal to that of the plagioclase seeds (Table 1). In most experiments on MORB, the $\mathrm{An}_{77}$-plagioclase seeds show equilibrium 
growth rims of $\mathrm{An}_{68}$. Slightly elevated $\mathrm{FeO}$ and $\mathrm{MgO}$ values in these analyses are most probably artifacts from exciting some surrounding melt, since the spot size had to be widened to $10 \mu \mathrm{m}$ for plagioclase. With the MOR-type basalt, only experiments gx49 and gx59 did not form any rim, but show slightly corroded $\mathrm{An}_{77}$ grains, a few of them dissociated into swarm-like grain agglomerates too fine to measure. Experiments on the evolved lunar composition yield plagioclase with a homogeneous $\mathrm{An}_{77}$ composition, without any rims, yet, gx 136 (Fig. 3a, Table 3) exhibits some dissociated grains. In the experiments on the lunar composition, a minor FeTi-oxide phase is also present, too small for quantitative analysis.

Adding plagioclase with $X_{\mathrm{An}}$ higher than the expected equilibrium anorthite content $\mathrm{An}_{71}$ (Villiger et al. 2007) helps avoiding extensive chemically driven dissolution and reprecipitation and hence changing grain shape and size during the experiments (see also Appendix II). Distribution coefficients $\left(K_{\mathrm{D}}=\operatorname{plag}_{\mathrm{Ca} / \mathrm{Na}} / \mathrm{liq}_{\mathrm{Ca} / \mathrm{Na}}\right.$ molar $)$ for plagioclase in anhydrous liquids are known to be approximately 1 at $<1$ GPa (Sisson and Grove 1993). The plagioclase rim-melt $K_{\mathrm{D}}$ of our experiments are on average $1.05 \pm 0.04$ (gx35, gxz33, 34, 40, 51, 54, 58, 61), consistent with the nominally dry system. The absence of significant $\mathrm{H}_{2} \mathrm{O}$ or $\mathrm{OH}$ bands in Raman spectra (see below) supports this finding. Rim compositions are considered to be in equilibrium with the melt.

\section{Stokes settling experiments ( 1 st set)}

Three experiments were run at $\sim 0.5 \mathrm{GPa}, 1220^{\circ} \mathrm{C}$ with a low crystal content of $10 \mathrm{wt} \%$. One experiment is static (gx35), two were centrifuged at $1000 \mathrm{~g}$ for 5 and $10 \mathrm{~h}$, respectively. In the static experiment, plagioclase crystals are randomly distributed across the capsule (Fig. 1a), while $10 \mathrm{~h}$ of centrifuging led to full settling with almost all crystals accumulated in a bottom layer with $73.3 \mathrm{vol} \%$ porosity (gxz33, Fig. 1c). Five hours of centrifuging (gxz34) yields 58 grains still suspended and dispersed above the bottom cumulate layer (75.8 vol\% porosity, Fig. 1b). Using a statistical average distribution, the average starting height of the 58 grains was reconstructed (horizontal line in Fig. 1b), and the $5 \mathrm{~h}$ at $1000 \mathrm{~g}$ then results in a settling distance of $1487 \pm 457 \mu \mathrm{m}$ for the still floating grains ( $n=58$, Fig. $1 \mathrm{~b})$.

Note that sticky forces always keep some crystals at the roof or wall of the capsule (e.g. Fig. 1c, likely following crystal growth at the capsule surface). These crystals may detach and sink at random points in time, and single "latecomers" are hence not used for quantifying settling rates.

\section{Plagioclase floatation and sinking in MOR-type basalt (second set)}

The second set of experiments was run with a 7:3 melt/plagioclase (initial weight proportion) mixture to obtain a maximum height and hence maximum gravitationally induced compaction of the plagioclase cumulate pile. Initial calculations predicted that this series would always float plagioclase, but the results show that neutral buoyancy occurs at $0.59 \mathrm{GPa}$.

The situation before centrifuging is characterized by the static experiments gx 49 (Fig. 2a, d) and gx59 (Fig. 2h), run for $48 \mathrm{~h}$ at $1225^{\circ} \mathrm{C}, 0.5 \mathrm{GPa}$ and $1250{ }^{\circ} \mathrm{C}, 1.0 \mathrm{GPa}$, respectively. Image analysis of the central portion yields a homogeneous melt distribution with $75.4 \pm 1.5$ and $74.0 \pm 1.5 \mathrm{vol} \%$, respectively, i.e. identical within error.

Centrifugation at $1000 \mathrm{~g}$ was conducted at $1225-1250^{\circ} \mathrm{C}$ and $0.48-0.84 \mathrm{GPa}$ (Fig. 2b, c, i, j). The effect of centrifugation is then the combined effect of acceleration $\mathrm{x}$ duration and melt-plagioclase density contrast $\left(\Delta \rho_{\text {plag-melt }}\right)$, the latter being extremely sensitive to pressure. After $3 \mathrm{~h}$ of centrifugation at $0.50 \mathrm{GPa}$ plagioclase did sink and the profile shows a gradient in porosity between the upper three segments (71-72\% porosity) and the lowermost one (66\% porosity; gxz58, $\Delta \rho_{\text {plag-melt }}=4 \mathrm{~kg} \cdot \mathrm{m}^{-3}$, Fig. $2 \mathrm{~b}$ ). This is likely a result from the lower part being fully settled, i.e. grains rest in contact with each other, while in the upper part settling is still progressing (Fig. 2b). Five hours of centrifugation at $0.50 \mathrm{GPa}$ (gxz54, $\Delta \rho_{\text {plag-melt }}=6 \mathrm{~kg} \cdot \mathrm{m}^{-3}$, Fig. $2 \mathrm{c}$ ) leads to a plagioclase-free melt area at the gravitational top of the capsule, and the cumulate pile itself has porosities decreasing downward from 67 to $60 \%$, a result of incipient compaction.

Two experiments with $5 \mathrm{~h}$ and $10 \mathrm{~h}$ of centrifugation at 0.84 and $0.62 \mathrm{GPa}$ and $1000 \mathrm{~g}$ show a floating plagioclase cumulate and a lower melt-only layer (gxz61, 0.84 $\mathrm{GPa}, \Delta \rho_{\text {plag-melt }}=-26 \mathrm{~kg} \cdot \mathrm{m}^{-3}$, and gxz51, $0.62 \mathrm{GPa}$, $\Delta \rho_{\text {plag-melt }}=-4 \mathrm{~kg} \cdot \mathrm{m}^{-3}$, Fig. $3 \mathrm{~b}$ and c). The bottom segments of the cumulate have porosities of 68 and $66 \%$, respectively, comparable to the top segment of most settling experiments $(67 \%)$. This indicates that a fully settled/floated but not compacted plagioclase cumulate with grains in contact, segregating gravitationally from a crystal suspension achieves a porosity of $67 \pm 2 \mathrm{vol} \%$ (mean of the top/bottom segments gxz51, 54, 61 and of the second segment of gxz58; the segments above are not fully settled yet).

The two plagioclase floatation experiments yielded also some compaction, albeit with a stronger porosity difference of $8.4 \%$ across the cumulate after $5 \mathrm{~h}(0.84 \mathrm{GPa})$ than the $5.6 \%$ observed after $10 \mathrm{~h}(0.62 \mathrm{GPa})$. This is readily explained with $0.84 \mathrm{GPa}$ being further away from neutral buoyancy (at $0.59 \mathrm{GPa}$ ) than $0.62 \mathrm{GPa}$; calculated (corrected) $\Delta \rho_{\text {plag-melt }}$ are -26 and $-4 \mathrm{~kg} \cdot \mathrm{m}^{-3}$, respectively. Note that density differences are not only a simple function 
(a)

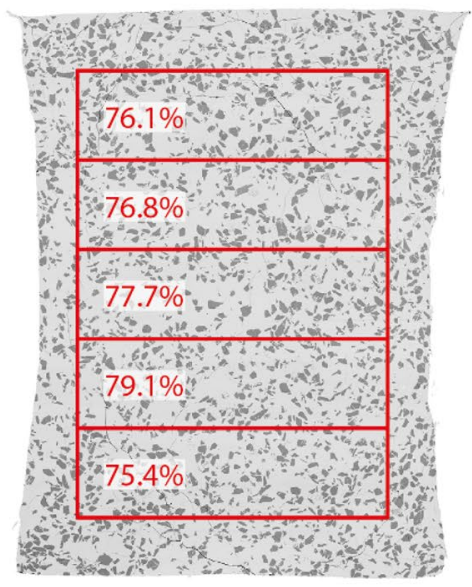

gx49 $500 \mu \mathrm{m}$

static $0.50 \mathrm{GPa}$

$\Delta \rho_{\text {plag-melt(corr.): }} 12\left(\mathrm{~kg} \cdot \mathrm{m}^{-3}\right)$

(d)

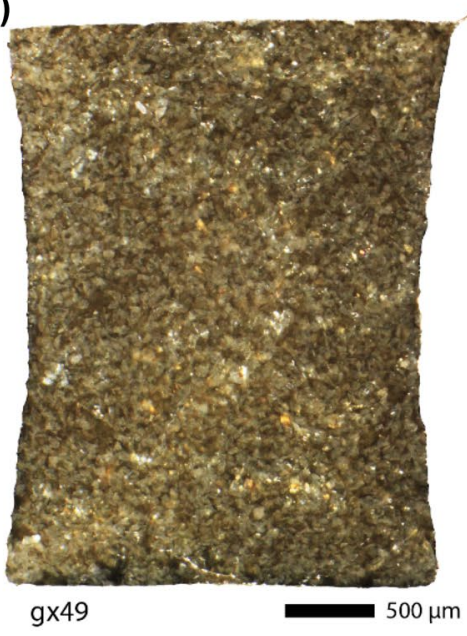

(h)

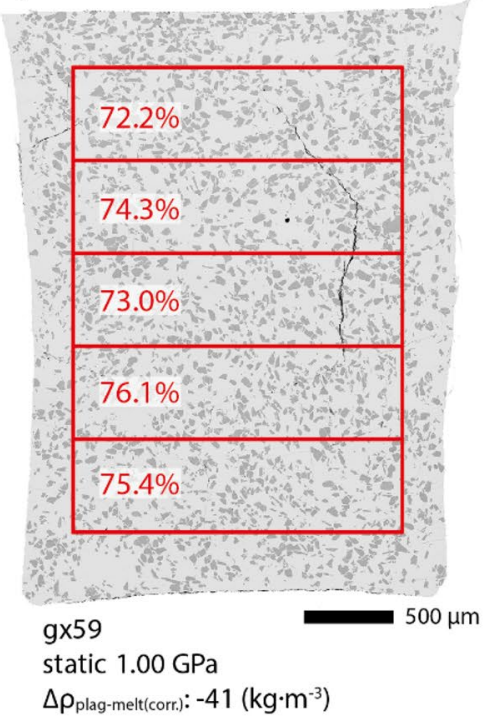

(b)

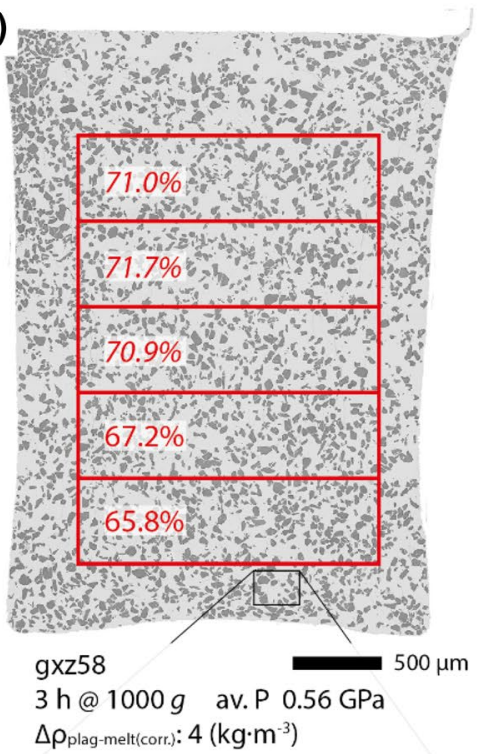

(e)

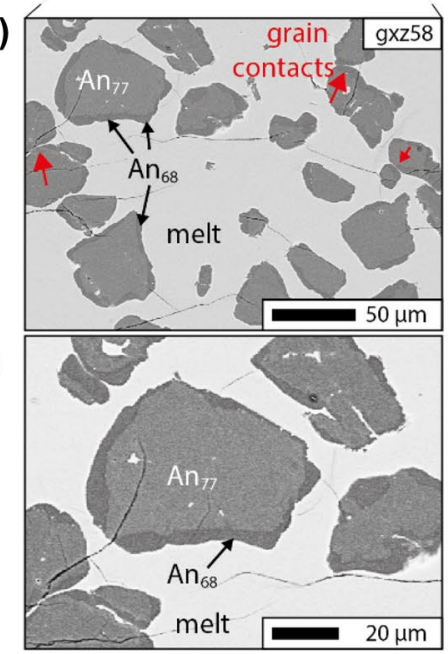

(i)

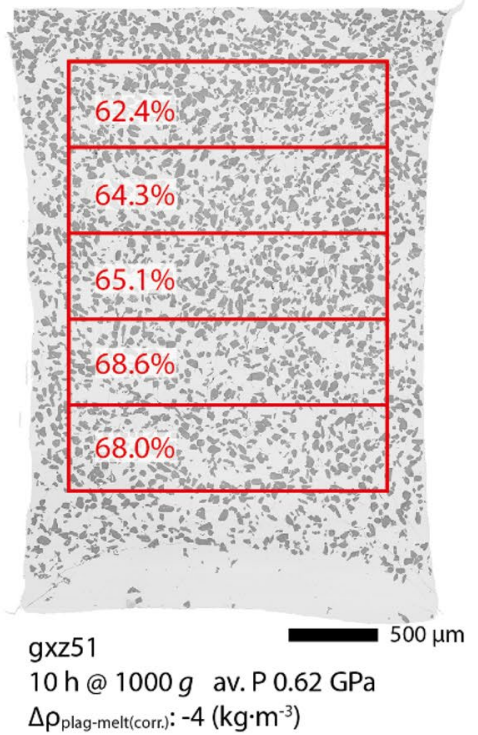

(c)

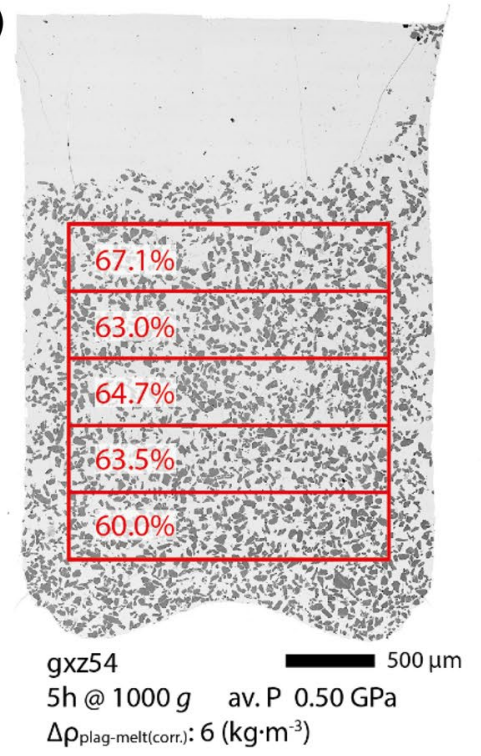

(g)

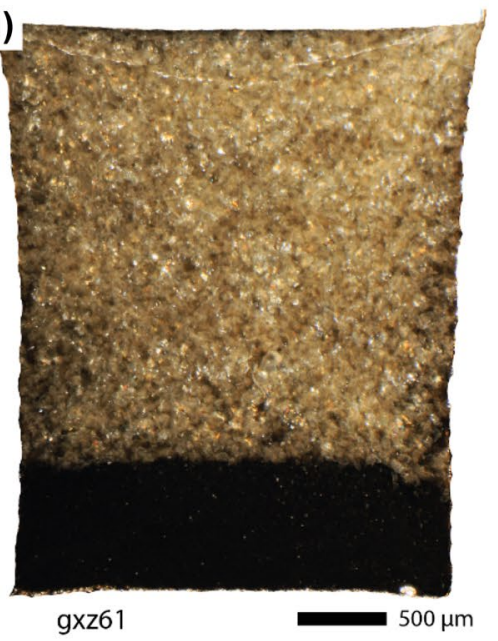

(j)

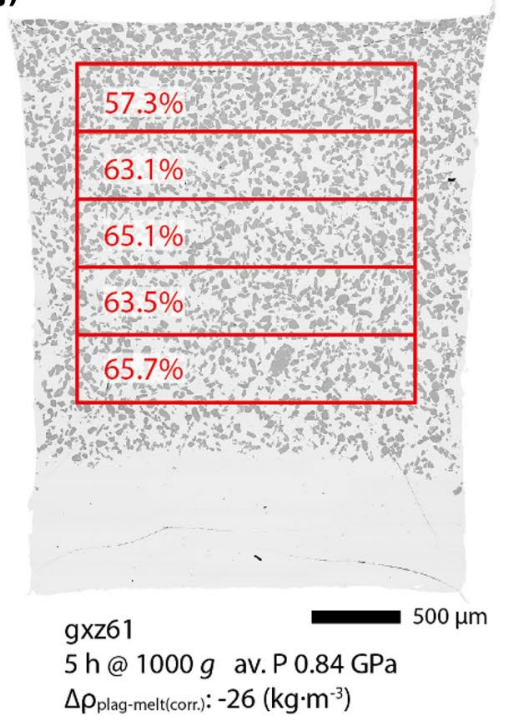


4Fig. 2 BSE and optical images of experiments on MOR-type basalt with 7:3 melt/plag at pressures of $0.50-1.00 \mathrm{GPa}, 1225-1250{ }^{\circ} \mathrm{C}$ in Ir capsules (white). Calculated $\Delta \rho_{\text {plag-melt(corr.) }}$ for this series are 12 to $-41 \mathrm{~kg} \cdot \mathrm{m}^{-3}$ and close to neutral buoyancy. The red areas depict the segments used for quantification, and labels are porosities or melt percentages. a Static experiment with negatively buoyant plagioclase showing a homogeneous plagioclase distribution. $\mathbf{b} 3 \mathrm{~h}$ of centrifugation at $1000 \mathrm{~g}$ leads to a fully settled bottom part and an upper part where first melt patches appear. This experiment is almost at neutral buoyancy, and plagioclase grains of the upper three layers are mostly not yet in contact with each other, hence still in suspension. c $5 \mathrm{~h}$ of centrifugation leads to fully settled plagioclase and a well-developed porosity profile. d Image using inclined reflected light of suspension gx59 (h). Details of the bottom of gxz58, e a few contact points between grains are visible, testifying for grains resting on each other, $\mathbf{f}$ left-hand upper corner detail of $\mathbf{e}$ with contrast adjusted to show the $\mathrm{An}_{68}$ growth rims. $\mathrm{g}$ Inclined reflected light image of gxz61 (j). h $1 \mathrm{GPa}$ static experiment with buoyant plagioclase yielding a homogeneous plagioclase distribution. i $10 \mathrm{~h}$ of centrifugation at $1000 \mathrm{~g}$; this experiment is again close to neutral buoyancy but a plagioclase free bottom layer formed. $\mathbf{j} 5 \mathrm{~h}$ of centrifugation at $1000 \mathrm{~g}$ resulting in a compacted floating plagioclase layer with a well-developed porosity profile

of $\Delta \mathrm{P}$ to neutral buoyancy but also depend on slight changes in melt composition caused by some reaction of plagioclase seeds and some Fe loss to the capsule.

\section{Plagioclase floatation in an evolved lunar magma ocean composition (third set)}

To maximize the density difference between plagioclase and melt, we selected a plagioclase-saturated melt composition with $25.7 \mathrm{wt} \% \mathrm{FeO}$ resulting from fractionating a lunar magma ocean (Table 1). A density difference between plagioclase and Fe-rich melt of $\Delta \rho_{\text {plag-melt }}=-268$ to $-287 \mathrm{~kg} \cdot \mathrm{m}^{-3}$ is already large enough to produce a crystal-free bottom layer in the static experiment ( $48 \mathrm{~h})$. In contrast to the static experiments on MOR-type basalt, some grain contacts can be observed and indicate that floatation occurred without centrifuging. The centrifuged experiment $(10 \mathrm{~h}$ at $1000 \mathrm{~g}$, Table 2) has then compacted to a porosity of $53 \%$ in the top layer, the smallest value observed in all experiments, a direct result of the large plagioclase-melt density contrast. The red arrows in Fig. 3c point to abundant visible grain contacts in the uppermost segment of the experiment. The plagioclase grains form a connected "grid," touching grain tips are dissolved, and the material presumably redeposited on free plagioclase faces in contact with melt.

\section{Calculated densities and neutral buoyancy, melt density correction}

Various methods were applied for calculation of melt and plagioclase densities and density contrast, the key variable in this study. The finally applied calculation schemes are outlined below.

\section{Melt density}

Our preferred method to calculate melt densities follows Bottinga and Weil (1970). Values for molar volumes (at $1400{ }^{\circ} \mathrm{C}$ ) and 1 bar thermal expansion are taken from Lange and Carmichael (1987) and $1400^{\circ} \mathrm{C}$ compressibilities from Kress and Carmichael (1991) as summarized in Lange and Carmichael (1990). The volumes at temperature and pressure are calculated and summed from the single melt components as follows:

$V_{\text {liq }}\left(T, P, X_{i}\right)=\sum X_{i}\left[V_{i, 1400^{\circ} \mathrm{C}}+d V_{i} / d T \cdot(T-1400)+d V_{i} / d P \cdot(P-0.001)\right]$,

where $X_{i}$ is the molar fraction of each melt component, $V_{\mathrm{i}, 1400{ }^{\circ} \mathrm{C}}$ the melt component reference volume at $1400{ }^{\circ} \mathrm{C}$, $T$ temperature in ${ }^{\circ} \mathrm{C}, P$ pressure in kbar, and $d V_{i} / d P_{1 \text { bar }}$ and $d V / d T_{1400^{\circ} \mathrm{C}}$ the pressure and temperature dependencies of each component's volume. For the few nonideal corrections $\left(\mathrm{Na}_{2} \mathrm{O}-\mathrm{TiO}_{2}\right.$ and $\left.\mathrm{Na}_{2} \mathrm{O}-\mathrm{Al}_{2} \mathrm{O}_{3}\right)$, the reader is referred to Kress and Carmichael (1991).

Two potentially important issues need yet to be dealt with: (i) oxidation state of iron and (ii) $\mathrm{H}_{2} \mathrm{O}$ in the melt.

1. All Fe in the starting material was ferrous; hence, in a closed system, the amount of ferric iron can be estimated from the $\mathrm{Fe}$ loss of the melt, $\mathrm{Fe}^{0}$ alloying with the Ir capsule leading to $\mathrm{Fe}^{\mathrm{III}}$. The relative $\mathrm{Fe}$ loss is on average $5.4 \mathrm{wt} \%$ relative to total $\mathrm{FeO}$ but ranges from almost nil to $10 \%$ relative leading to (absolute) $1.2 \pm 1.1$ wt $\% \mathrm{Fe}_{2} \mathrm{O}_{3}$ in the melts of the first and second sets. This would decrease melt densities only by $4.1 \pm 3.8(1 \sigma) \mathrm{kg}$ $\mathrm{m}^{-3}$. This minor effect was not further considered, in particular as the critical experiments at 0.56 and 0.62 $\mathrm{GPa}$ had only 4.7 and $0.5 \mathrm{wt} \%$ relative Fe loss (corresponding to -3.5 and $-0.4 \mathrm{~kg} \mathrm{~m}^{-3}$, respectively).

2. The experiments were nominally dry, but residual $\mathrm{H}$ may be present at the start or diffuse in through the capsule wall (from the piston cylinder assembly). In order to test whether any detectable $\mathrm{H}_{2} \mathrm{O}$ was present in the experimental glasses, $\mathrm{H}_{2} \mathrm{O}$ was checked by Raman spectroscopy in the glasses of two long duration runs (gxz40, gxz54), which potentially would have the largest amount of in-diffusing hydrogen. Nevertheless, neither $\mathrm{H}_{2} \mathrm{O}$ nor $\mathrm{OH}$ bands could be found (Appendix IV). The detection limit of Raman is about $0.1 \mathrm{wt} \% \mathrm{H}_{2} \mathrm{O}$ (Le Losq et al. 
(a)

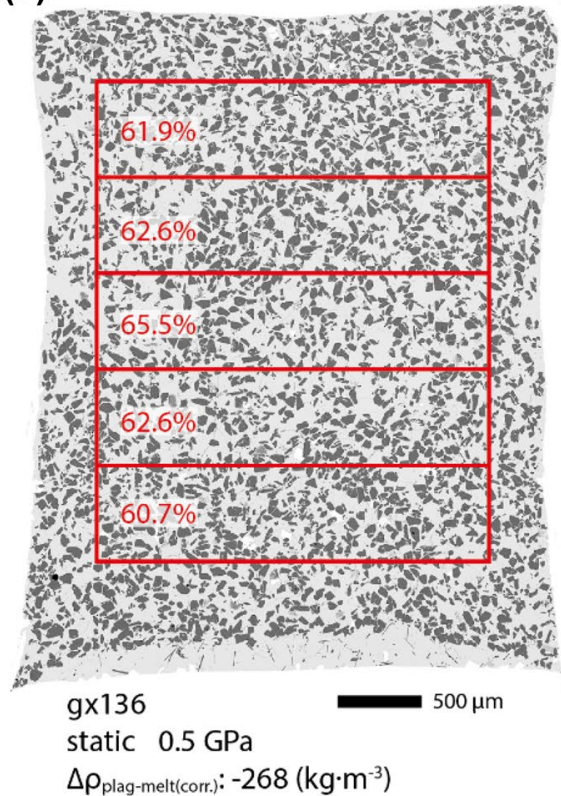

(b)

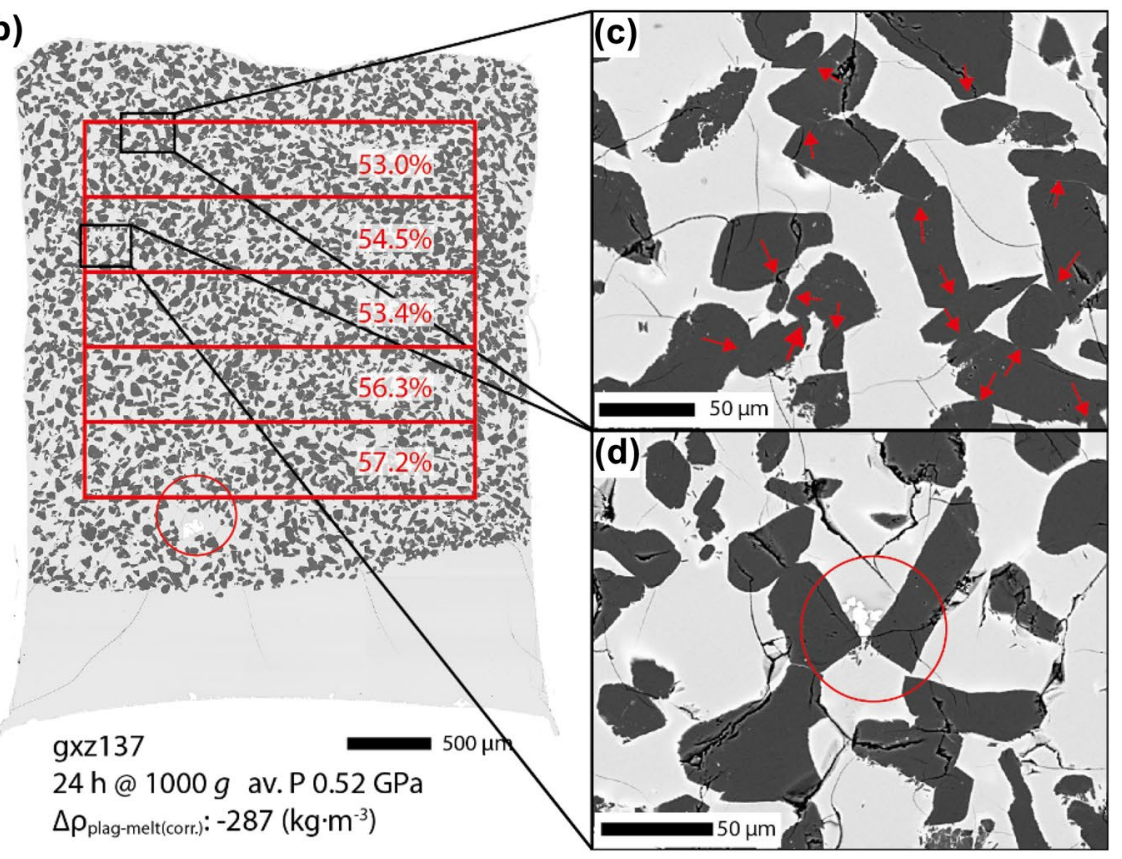

Fig. 3 BSE images of 7:3 melt/plag floating experiments with an Fe-rich evolved lunar magma ocean melt (twm9, Table 1); $0.5 \mathrm{GPa}$, $1140{ }^{\circ} \mathrm{C}$, Ir capsules. The red lines depict segments or layers used for quantification, the red labels give porosity or melt percentages. a The larger density contrast with the melt already yields a small crystal free layer in the $48 \mathrm{~h}$ run at ambient gravitation. Note that the hot spot is centered on the capsule, in these experiments, temperature distribution apparently does not govern melt distribution. b Additional $24 \mathrm{~h}$ of centrifugation at $1000 \mathrm{~g}$ leads to a well-compacted cumulate with

2012), and we conclude that there is less than $0.1 \mathrm{wt} \%$ $\mathrm{H}_{2} \mathrm{O}$ in the glasses, an amount that would lessen the glass density by about $5 \mathrm{~kg} \mathrm{~m}^{-3}$, utterly insufficient to explain the difference between the calculated and experimental density crossover of plagioclase and melt.

We hence conclude that the average microprobe analyses of the melt with all iron as $\mathrm{FeO}$ and $\mathrm{no}_{2} \mathrm{O}$ represent the true melt composition. The calculated experimental melt densities are then 2664-2746 $\mathrm{kg} \mathrm{m}^{-3}$ for the MOR-type basalt and 2960-2980 $\mathrm{kg} \mathrm{m}^{-3}$ for the lunar melt composition (Table 2).

In principal, there is also a temperature dependence of the pressure derivative of the molar volume $\left(d V_{i} / d P\right) d T$ (Kress and Carmichael 1991; Ochs and Lange 1997, 1999). Including this term leads to an even higher calculated density of the MORB-type glasses of this study, which would further aggravate the discrepancy between calculated and experimental density crossover. As $\left(d V_{i} / d P\right) d T$ is highly uncertain, we preferred to not apply this derivative. The tonalite melt model of Green et al. (2016) was tested for comparison using perpleX (Connolly 2005) with the thermodynamic database of Holland and Powell (2011). This model results in melt densities that are higher by about $+26 \mathrm{~kg} \cdot \mathrm{m}^{-3}$ (without $\mathrm{TiO}_{2}$, not included a top segment porosity of $53 \mathrm{vol} \%$. c Detail of the uppermost segment of gxz137 showing abundant grain contacts. d Detail of sinking oxides in gxz137 caught in troughs in between plagioclase grains. In these experiments, plagioclase floats, while the oxides sink. The generally much smaller size of the oxides leads to negligible forces, except for the one big oxide grain aggregate indicated by the arrow just below the lowermost segment in (b), where the oxide grain aggregate leaves a melt pool in its wake

in the model) compared to those derived using Lange and Carmichael (1990). The molar volume per oxygen of $\mathrm{TiO}_{2}$ is most similar to that of $\mathrm{MgO}$; hence, when recalculating all $\mathrm{TiO}_{2}$ as $2 \mathrm{MgO}$, melt densities increase by as much as $+44 \mathrm{~kg} \cdot \mathrm{m}^{-3}$. Consequently, the Green et al. (2016) model exacerbates the misfit between the calculated and experimentally observed density crossover between plagioclase and melt.

\section{Plagioclase density}

Plagioclase densities are calculated in two steps: first, the density at zero pressure at the temperature of interest is determined $\left(\rho_{T, 0}\right)$ using the formulation of Fei (1995) and the constants $\left(a_{0}, a_{1}, a_{2}\right)$ listed in Table 4:

$\alpha(T)=a_{0}+a_{1} T+a_{2} T^{-2}$,

where $T$ is the temperature of interest (in $\mathrm{K}$ ) and $\alpha(T)$ the thermal expansion implemented in:

$\rho_{T, 0}=\rho_{298}(T) \exp \left[\int_{298}^{T} \alpha(T) d T\right]$. 


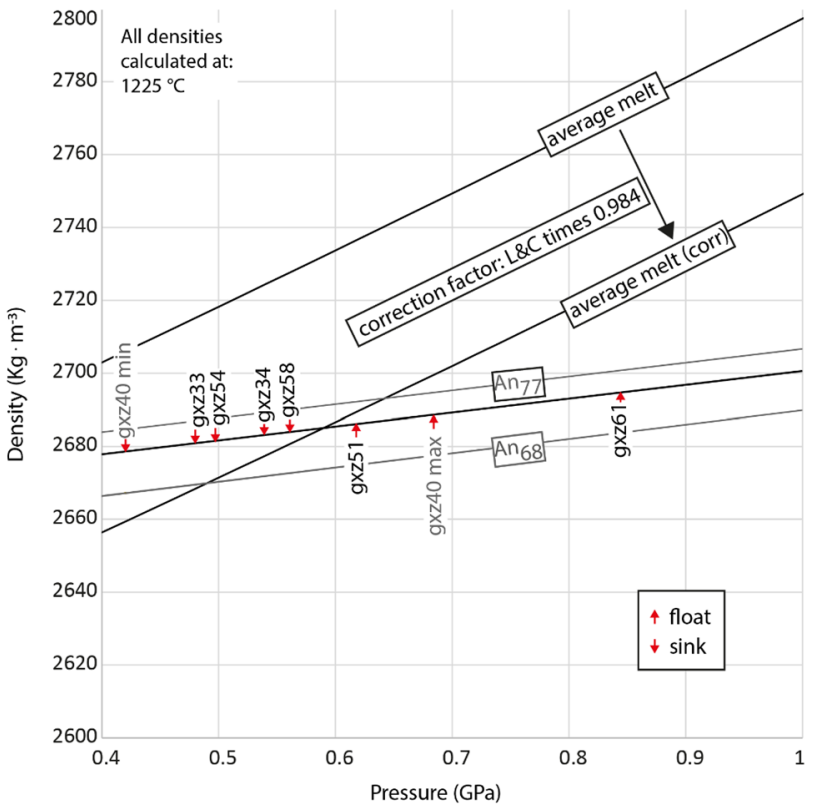

Fig. 4 Calculated mineral and melt densities at $1225^{\circ} \mathrm{C}$ and experimental pressures. The red arrows show the density and experimental behavior of plagioclase with respect to the melt. The plagioclase density is calculated as 2/3 core (of $A n_{77}$ ) and 1/3 rim (of $\mathrm{An}_{68}$ composition, see text). "Average melt" represents the density of the equilibrated melt calculated after Lange and Carmichael (1990). The offset of this composition at $0.59 \mathrm{GPa}$ to the density of the experimental plagioclase (bold line) was used to calculate a density correction factor of 0.984 . Gxz40 was run for $50 \mathrm{~h}$ at $1000 \mathrm{~g}$, and lost, due to its long centrifugation time, considerably pressure, gxz40 "max" and "min" mark the nominal pressure conditions at the beginning and end of the run. For all other experiments, pressure loss was small, and average pressures are used

Table 3 Averaged experimental melt and plagioclase compositions (individual compositions in Appendix I)
Density $\left(\rho_{T, P}\right)$ is then evaluated by iteratively solving a Birch-Murnaghan equation of state until the desired pressure $P$ (GPa) is found. As $K_{298}$ (Angel 2004) is chosen with $K^{\prime}=4$, the Birch-Murnaghan equation simplifies to:

$P=\frac{3}{2} K_{T}\left[\left(\frac{\rho_{T, P}}{\rho_{T, 0}}\right)^{\frac{7}{3}}-\left(\frac{\rho_{T, P}}{\rho_{T, 0}}\right)^{\frac{5}{3}}\right]$,

where $K_{T}(\mathrm{GPa})$ is the bulk modulus:

$K_{T}=K_{298}+\frac{\delta K}{\delta T}(T-298)$,

and $K_{298}$ is the isothermal bulk modulus and $\frac{\delta K}{\delta T}$ its temperature derivative (temperature in K). $K_{298}, K^{\prime}$ and $\frac{\delta K}{\delta T}$ values for high albite and anorthite are listed in Table 4. As generally used, an ideal volume of mixing is employed for the plagioclase solid solution.

There is some disparity in the literature concerning the reference molar volume of high albite (hAb, all our experiments lying in the hAb stability field), which yield density differences for the albite end member of ca. $25 \mathrm{~kg} \mathrm{~m}^{-3}$. Fortunately, this has relatively little influence, since our plagioclase is anorthite-rich. The preferred reference molar volumes of $\mathrm{hAb}=100.45$ and $\mathrm{An}=100.61 \mathrm{~cm}^{3} \mathrm{~mol}^{-1}$ (Table 4) are taken from Smyth and McCormick (1995) for consistency with the thermal expansion values of Fei (1995). For the bulk modulus $K_{298}$, the values of Angel (2004) are used. The temperature derivatives $\frac{\delta K}{\delta T}$ are calculated for $K^{\prime}=4$ using the Grüneisen parameter as in Abers and Hacker (2016). For the $P-T-X_{\mathrm{An}}$ range of interest, this calculation scheme yields ca. $-1.7 \mathrm{~kg} \mathrm{~m}^{-3}$ lower, yet very similar densities as in Abers

\begin{tabular}{|c|c|c|c|c|c|c|c|c|c|c|}
\hline \multirow[t]{3}{*}{$\mathrm{wt} \%$} & \multicolumn{6}{|c|}{ 1st, 2nd set of experiments } & \multicolumn{4}{|c|}{ 3rd set of (lunar) experiments } \\
\hline & \multicolumn{2}{|l|}{ Melt } & \multicolumn{4}{|c|}{ Plagioclase } & \multicolumn{2}{|l|}{ Melt } & \multicolumn{2}{|c|}{ Plagioclase } \\
\hline & & $1 \sigma$ & Core & $1 \sigma$ & Rim & $1 \sigma$ & & $1 \sigma$ & & $1 \sigma$ \\
\hline$n$ (number of analyses) & 120 & & 117 & & 34 & & 20 & & 26 & \\
\hline $\mathrm{SiO}_{2}$ & 52.3 & 0.8 & 48.6 & 0.7 & 51.9 & 0.7 & 44.2 & 0.6 & 48.5 & 0.5 \\
\hline $\mathrm{TiO}_{2}$ & 0.96 & 0.04 & 0.12 & 0.05 & 0.10 & 0.04 & 3.78 & 0.17 & 0.13 & 0.01 \\
\hline $\mathrm{Al}_{2} \mathrm{O}_{3}$ & 17.7 & 0.5 & 32.7 & 0.5 & 30.1 & 0.6 & 10.9 & 0.6 & 32.7 & 0.4 \\
\hline $\mathrm{FeO}$ & 8.49 & 0.42 & 0.40 & 0.05 & 0.59 & 0.30 & 23.7 & 0.2 & 0.73 & 0.08 \\
\hline $\mathrm{MnO}$ & bdl & - & bdl & - & bdl & - & 0.77 & 0.04 & bdl & - \\
\hline $\mathrm{MgO}$ & 6.83 & 0.29 & 0.13 & 0.03 & 0.29 & 0.25 & 4.80 & 0.11 & 0.04 & 0.02 \\
\hline $\mathrm{CaO}$ & 10.6 & 0.4 & 15.6 & 0.4 & 13.5 & 0.3 & 10.1 & 0.2 & 15.4 & 0.3 \\
\hline $\mathrm{Na}_{2} \mathrm{O}$ & 2.85 & 0.08 & 2.40 & 0.21 & 3.47 & 0.20 & 1.36 & 0.08 & 2.45 & 0.16 \\
\hline $\mathrm{K}_{2} \mathrm{O}$ & 0.32 & 0.01 & 0.03 & 0.02 & 0.07 & 0.02 & 0.14 & 0.03 & 0.03 & 0.01 \\
\hline Tot summe & 100.0 & & 100.0 & & 100.0 & & 100.0 & & 100.0 & \\
\hline Normalized feldspar content & 45 & & - & & - & & 25 & & - & \\
\hline$X_{\mathrm{An}}(\mathrm{Ca} /(\mathrm{Na}+\mathrm{Ca})$ molar $)$ & 0.67 & & 0.78 & & 0.68 & & 0.80 & & 0.78 & \\
\hline$X_{\mathrm{Mg}}(\mathrm{Mg} /(\mathrm{Mg}+\mathrm{Fe})$ molar $)$ & 0.59 & & - & & - & & 0.27 & & - & \\
\hline Viscosity at $1225^{\circ} \mathrm{C}(\mathrm{Pa} \cdot \mathrm{s})$ & 54 & & - & & - & & 19 & & - & \\
\hline
\end{tabular}

$b d l$ below detection limit 
Table 4 Parameters for calculating plagioclase densities

\begin{tabular}{lllllllllllllll}
\hline & $\begin{array}{l}\mathrm{V}_{0} \\
\mathrm{~cm}^{3} \cdot \mathrm{mol}^{-1}\end{array}$ & $\begin{array}{l}\text { Refer- } \\
\text { ences }\end{array}$ & $\begin{array}{l}\rho_{0} \\
\mathrm{~kg} \cdot \mathrm{m}^{-3}\end{array}$ & $\begin{array}{l}\alpha_{0} \\
10^{-5}\end{array}$ & $\begin{array}{l}\alpha_{1} \\
10^{-9}\end{array}$ & $\begin{array}{l}\alpha_{2} \\
10^{-1}\end{array}$ & $\begin{array}{l}\text { Refer- } \\
\text { ences }\end{array}$ & $\begin{array}{l}\mathrm{K}_{298} \\
\mathrm{GPa}\end{array}$ & $\begin{array}{l}\mathrm{K}{ }^{\prime}(\delta \mathrm{K} / \delta \mathrm{P}) \\
-\end{array}$ & $\begin{array}{l}\text { Refer- } \\
\text { ences }\end{array}$ & $\begin{array}{l}\delta \mathrm{K} / \delta \mathrm{T} \\
\mathrm{GPa} \cdot \mathrm{K}^{-1}\end{array}$ & $\begin{array}{l}\text { Refer- } \\
\text { ences }\end{array}$ & $\begin{array}{l}\rho_{1225}{ }^{\circ} \mathrm{C}, 0.59 \mathrm{GPa} \\
\mathrm{kg} \cdot \mathrm{m}^{-3}\end{array}$ \\
\hline $\begin{array}{c}\text { Albite } \\
\text { (high) }\end{array}$ & 100.45 & $\mathrm{a}, \mathrm{b}$ & 2610.4 & 2.455 & 7.621 & 0.000 & $\mathrm{~b}, \mathrm{~d}, \mathrm{e}, \mathrm{f}$ & 57.7 & 4 & & $g$ & -0.0065 & $\mathrm{~h}, \mathrm{i}, \mathrm{j}$ & $\mathbf{2 5 4 3}$ \\
$\begin{array}{c}\text { Anor- } \\
\text { thite }\end{array}$ & 100.61 & $\mathrm{a}, \mathrm{c}$ & 2765.2 & 1.390 & 1.700 & 0.000 & $\mathrm{f}$ & 81.7 & 4 & $\mathrm{~g}$ & & -0.0051 & $\mathrm{~h}, \mathrm{i}, \mathrm{j}$ & $\mathbf{2 7 3 5}$ \\
\hline
\end{tabular}

Data from: (a) Smyth and McCormick (1995); (b) Winter et al. (1979), (c) Wainwright and Starkey (1971); (d) Fei (1995); (e) Prewitt et al. (1976), (f) Tribaudino (2010); (g) Angel (2004); (h) Abers and Hacker (2016), (i) Holland and Powell (1998); (j) Bina and Helfferich (1992)

and Hacker (2016) but ca. $15.3 \mathrm{~kg} \mathrm{~m}^{-3}$ higher plagioclase densities than the Newton et al. (1980) feldspar model used by Holland and Powell (2011) as implemented in PerpleX (Connolly 1990, 2005). Obtaining the bulk plagioclase composition in the experiments is somewhat complicated because plagioclase seeds of $\mathrm{An}_{77}$ have sometimes rims of $\mathrm{An}_{68}$. From image analysis, these thin rims were found to amount on average to $32.4 \pm 2.5 \mathrm{vol} \%$ (rotational volumes, average and $1 \sigma$ of gxz $40,51,54,58,61$ ), but uneven amounts are observed on each crystal (Fig. 2f). For all following calculations of experiments with plagioclase growth rims, we used a density representing $2 / 3 \mathrm{An}_{77}$ plus $1 / 3 \mathrm{An}_{68}$. The density difference between $\mathrm{An}_{77}$ and $\mathrm{An}_{68}$ amounts to $17.4 \mathrm{~kg} \mathrm{~m}^{-3}$, a maximum uncertainty on the chemical composition of the plagioclase of $20 \%$ relative $\mathrm{An}_{77}: \mathrm{An}_{68}$ resulting in an uncertainty of the plagioclase density of $0.14 \%$.

\section{Density crossover and melt density correction}

The experiments demonstrate that plagioclase in a MORtype basaltic melt is negatively buoyant to $0.56 \mathrm{GPa}$ but floats at $0.62 \mathrm{GPa}$. As illustrated in Fig. 4, the experimentally determined pressure of neutral buoyancy $\left(\right.$ at $1225^{\circ} \mathrm{C}$ ) is $0.59 \pm 0.04 \mathrm{GPa}$, contrasting the calculated 0.10 or 0.15 GPa using $\mathrm{An}_{77}$ vs. the initial stg 3 melt or a mixture of $2 / 3$ $A n_{77}+1 / 3 A n_{68}$ and the average experimental melt, respectively. Although the pressure of neutral buoyancy depends on plagioclase and melt compositions, this finding, i.e. neutral buoyancy at $\sim 0.6 \mathrm{GPa}$, generally applies to relatively dry tholeiitic melts as relevant for mid-ocean ridges and layered mafic intrusions at conditions when plagioclase becomes voluminous.

The density of the plagioclase solid solution at pressure and temperature is comparatively well constrained through $\mathrm{X}$-ray diffraction, typical errors of standard state volume, expansivities and compressibilities (Table 4) being in the per mille range. We consider that melt volumes are intrinsically less precise. At the experimentally observed pressure of neutral buoyancy $(0.59 \mathrm{GPa})$, plagioclase density is $2685 \mathrm{~kg} \mathrm{~m}^{-3}\left(2 / 3 \mathrm{An}_{77}, 1 / 3 \mathrm{An}_{68}\right)$, while the calculated melt density is $2728 \mathrm{~kg} \mathrm{~m}^{-3}$. Accordingly, molar melt volumes need correction by $+1.6 \%$, yielding a melt density correction factor of 0.984 . We cannot constrain whether the larger part of the required correction is in the partial molar volumes or in $d V / d P$, but suspect the error is in the compressibility. The aforementioned alternative density models (melt density of Green et al. (2016) combined with plagioclase density of Newton et al. (1980)) result in an even larger correction.

\section{Settling velocity, orthocumulate porosity and compaction}

Early experiments (see Appendix II) were run with small plagioclase grain sizes of $10-15 \mu \mathrm{m}$, similar to our previous studies on olivine and chromite (Manoochehri and Schmidt 2014; Schmidt et al. 2012). These experiments did not segregate a cumulate layer after $10 \mathrm{~h}$ at $700 \mathrm{~g}$, such that the starting grain size was increased to $30-40 \mu \mathrm{m}$.

\section{Settling velocities}

Stokes Law (Stokes 1851) describes the movement of spherical objects in a viscous medium:

$v_{s}=\frac{1}{18} \frac{d^{2} \cdot \Delta \rho \cdot a}{\mu}$

where $v_{\mathrm{s}}$ is the settling velocity, $d$ the diameter, $\Delta \rho$ the density contrast between object and liquid, $a$ acceleration and $\mu$ viscosity. Experiment gxz34 yielded a travel distance of $1487 \pm 457 \mu \mathrm{m}$ for $5 \mathrm{~h}$ at $1000 \mathrm{~g}$ (Fig. 1b). In this experiment, melt viscosity $\mu_{\text {melt }}$ is $69 \mathrm{~Pa} \cdot \mathrm{s}$ (Giordano et al. 2008), densities are $\rho_{\text {plag }}=2684 \mathrm{~kg} \mathrm{~m}{ }^{-3}$ and $\rho_{\text {melt-corr }}=2674 \mathrm{~kg} \cdot \mathrm{m}^{-3}$ and hence the density contrast $\Delta \rho_{\text {plag-melt }}=10 \mathrm{~kg} \mathrm{~m}^{-3}$. The average (uncorrected) particle length of experiment gxz34 is $39 \pm 15 \mu \mathrm{m}(1 \sigma, n=58)$, yielding a Stokes settling velocity $\mathrm{v}_{\mathrm{s}}$ of $1.2(8) \cdot 10^{-10} \mathrm{~m} \cdot \mathrm{s}^{-1}$ (uncertainties on $\Delta \rho_{\text {plag-melt }}$ and $\mu_{\text {melt }}$ not considered). In contrast, the 58 grains of gxz34 settle with a velocity of $v_{(\varphi c)}=8.3(2.5) \cdot 10^{-11} \mathrm{~m} \mathrm{~s}^{-1}$ (scaled to $1 \mathrm{~g}$ ), a factor 1.5 slower. This slower settling velocity can be attributed to settling in suspension or to the nonspherical shape of the plagioclase grains. Using a characteristic "length," in our case the average length of the particles, 
should sufficiently correct for the shape effect (McNown and Malaika 1950) as long as the flow regime remains laminar, which is likely for our low Reynolds number system. The particles in the experiments hence sink with a "hindered settling velocity" $v_{(\varphi c)}$ (Richardson and Zaki 1954; Tomkins et al. 2005), which depends on the crystal content:

$v_{(\varphi c)}=v_{s} \cdot\left(1-\varphi_{c}\right)^{n}$,

with $v_{\mathrm{s}}$ the theoretical Stokes settling velocity, $\varphi_{\mathrm{c}}$ the crystal fraction in the suspension and $n$ the sedimentation exponent. The suspension load is $8.3 \mathrm{vol} \%$ yielding a sedimentation exponent of 4.3 (9). This exponent is similar to 4.1 and higher than 2.4 as determined for olivine and chromite in previous experiments (Manoochehri and Schmidt 2014; Schmidt et al. 2012). These differences may arise from two effects: first, the sedimentation exponent increases with deviation from a spherical shape, and secondly, it decreases with increasing density difference, hence increasing settling velocity (Baldock et al. 2004; Richardson and Zaki 1954; Rowe 1987; Tomkins et al. 2005). The morphologies of plagioclase and olivine grains in the experiments are comparable, and the chromite grains are distinctly more spherical and have a much higher density contrast.

\section{Orthocumulate porosity and formation time}

The depositional packing densities reached in experiments of the second set where plagioclase grains in the top segment have just fully settled but not yet compacted vary from 0.66 to 0.68 with an average porosity or melt fraction of $\varphi_{\mathrm{m}}=0.67$ (gxz51, gxz54, gxz61, second segment of gxz58, compare Fig. 2). Knowing the porosity of a plagioclase orthocumulate, its formation time $t_{\text {ortho }}$ may be calculated from the initial crystal content $\varphi_{\mathrm{c}}$ and the hindered settling velocity $v_{(\varphi \mathrm{c})}$ according to

$t=\left(h \cdot\left(1-\varphi_{m}\right) / \varphi_{c}-h\right) / v_{\left(\varphi_{c}\right)}$,

where $h$ is the thickness of the resulting orthocumulate layer. Initial suspension loads in magma chambers cooling from super-liquidus conditions are thought to be small, and taking $\varphi_{c}=0.01, d=5 \mathrm{~mm}, \mu=10 \mathrm{~Pa} \cdot \mathrm{s}$ and $\Delta \rho 50 \mathrm{~kg} \cdot \mathrm{m}^{-3}$ as characteristic values leads to formation of a $10 \mathrm{~m}$ plagioclase orthocumulate layer within 57 days. The height of the magma layer required is defined through the initial crystal content and the orthocumulate density and is in this example $330 \mathrm{~m}$. Overall, the hindering in the settling of dense mineral suspensions in layered intrusions is small. Given the fact that settling over hundreds of meters for 5-10-mm-large grains in a basaltic liquid takes less than a year, a slowing down of $10-50 \%$ appears negligible in the context of large mafic magma chambers.
Characteristic cooling times of basaltic sills following Turcotte and Schubert (2002) are 10-20 years for a 20-m-thick sill, depending on the country rock temperature. LMIs have far larger dimensions and with time higher boundary temperatures of the magma chamber (e.g. through repeated magma recharge); more realistic timescales are in the range of hundreds to ten thousands of years (Irvine 1970). Hence, even in thin sills the formation of plagioclase orthocumulates by grain settling is a plausible process.

\section{Surface of the cumulate layer and grain rotation}

Experiment gxz40 was designed for long-duration compaction $(50 \mathrm{~h}$ at $1000 \mathrm{~g})$. Unfortunately, this experiment had a small, but constant rate of decreasing pressure that resulted in conditions crossing the pressure of neutral buoyancy. The result, with at the end negatively buoyant plagioclase, is a top boundary layer with a significantly lower porosity of 49.8 vol\% than in the lower layers with 61.5-66.8 vol\% (Fig. 5). Consequently, this experiment cannot be used for quantification but its most prominent features merit discussion:

1. The dense top boundary layer of the cumulate has the lowest porosity, but also a notably lower grain size with a long axis average of $22 \pm 16 \mu \mathrm{m}$ compared to $29 \pm 18 \mu \mathrm{m}$ for the other layers (Fig. $5 \mathrm{~b}$ ). Image processing also reveals a more pronounced preferred grain orientation with $60.5 \%$ of the long axis at $<45^{\circ}$ to the horizontal compared to $41-54 \%$ for the other layers. For this preferred grain orientation, only grains with an aspect ratio greater than 2 were taken into account (Fig. 5c).

2. At the capsule's top (Fig. 5a and b), above the crystalfree melt layer, there are 2-3 grains thick plagioclase clumps sticking to the capsule roof. Single sticking crystals were observed in most experiments but an almost coherent layer otherwise not. This layer is apparently the consequence of pressing the crystals toward the roof in the first $\sim 10 \mathrm{~h}$ of the experiment, when plagioclase was floating.

Compared to random grain orientation, preferred grain orientation of platy crystals leads to lower porosity. The preferred grain orientation is the result of grain rotation, very likely enabled at the free top surface of the cumulate where later sedimented grains interfere less and hence block rotation to a lesser degree. Although grain size itself does not change porosity, grain size sorting may have a large influence (e.g. Schwindinger 1999). The top boundary layer of gxz40 has more flat-lying grains, a substantially lower average grain size, and most importantly, a different grain size distribution with more small grains and less large grains compared to the lower segments (Fig. 5). 


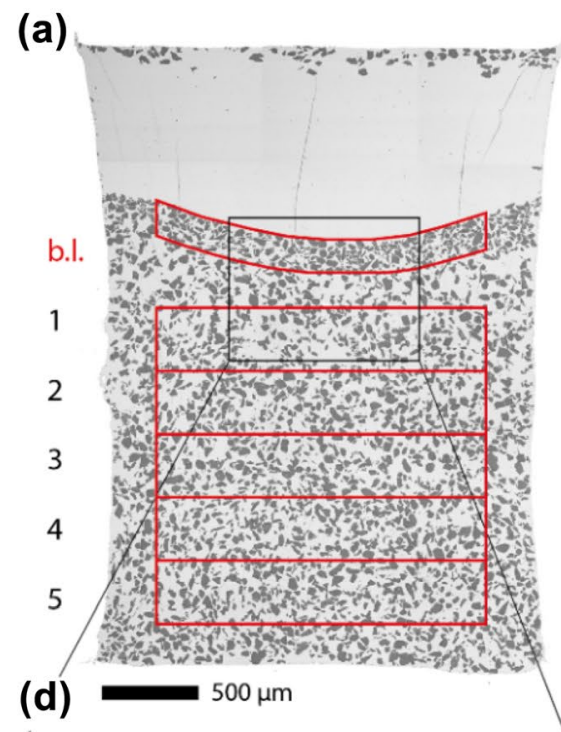

(b)

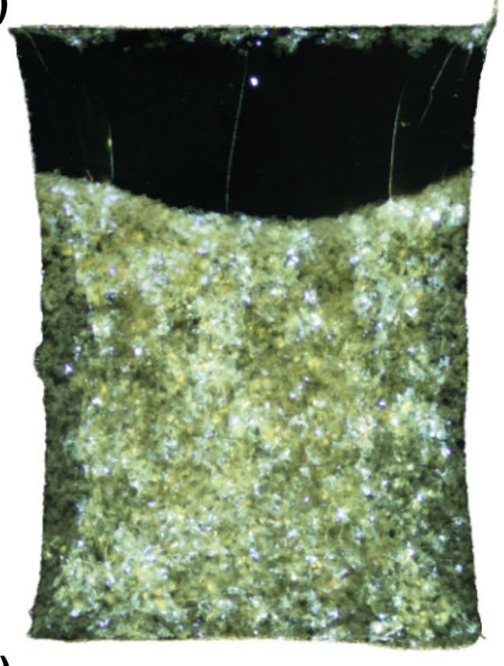

(e)

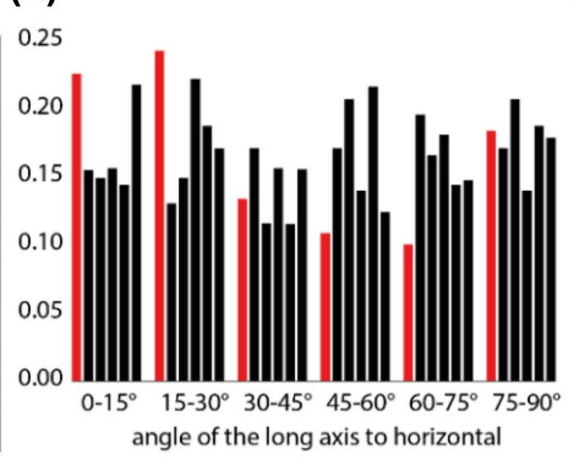

(c)

$\begin{array}{cccc}\text { (c) porosity } & \begin{array}{c}\text { average } \\ \text { grain-size } \\ \text { (long axis) } \\ \text { area } \%\end{array} & \begin{array}{c}\text { number of } \\ \text { grains }\end{array} \\ \text { b.l. } & 49.8 & 22 \pm 16 & \mathrm{n} \\ 1 & 66.8 & 28 \pm 17 & 369 \\ 2 & 62.4 & 29 \pm 18 & 357 \\ 3 & 62.5 & 28 \pm 18 & 367 \\ 4 & 61.5 & 29 \pm 19 & 382 \\ 5 & 62.9 & 22 \pm 22 & 345\end{array}$

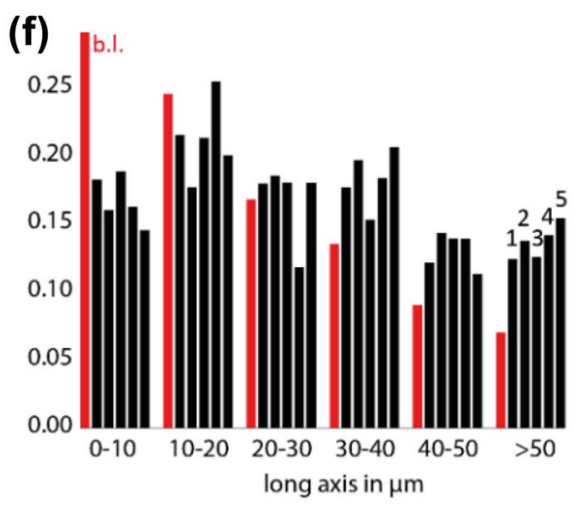

Fig. 5 Experiment gxz40 with $50 \mathrm{~h}$ of centrifugation during which pressure dropped across neutral buoyancy $\left(P_{\max } 0.68 \mathrm{GPa}\right.$ to $P_{\min }$ $0.42 \mathrm{GPa} \Delta \rho_{\text {plag-melt }}:-6$ to $23 \mathrm{~kg} \mathrm{~m}^{-3}$ ). The upper boundary layer (bl) has the lowest porosity throughout the cumulate, probably an effect of grain sorting and rotation. a BSE image with analyzed segments. b Optical image (shadows along the walls are due to the cylin- drical shape of the sample). d Detail showing a higher grain density for the top boundary layer. e Angle of the long plagioclase axis with respect to the horizontal for each segment (normalized number of grains on the $y$-axis) and $\mathbf{f}$ Histogram of grain size distribution (long axis). In $\mathbf{e}$ and $\mathbf{f}$, values of the boundary layer are in red, followed by the five other segments (as depicted in (a)) from top to bottom
In summary, experiment gxz40 shows that grain rotation and sorting increase the settling density of an orthocumulate. The change in settling direction during this experiment led to a different grain size distribution than in all other experiments and allowed for more time for grain rotation at the top of the plagioclase sediment causing a distinctly denser orthocumulate with $\varphi=49.8$ vol\% (Fig. 5a). From this experiment, we conclude that settling porosities may also depend on the growth rate of the cumulate layer, a slower growing boundary allowing for more grain rotation.

\section{Compaction of plagioclase cumulates}

Porosity profiles (Fig. 6a) were measured, by segmenting the cumulate (Figs. 2 and 3) into five layers, for all experiments with an initial 7:3 melt/plag ratio. Because of the relatively large plagioclase grain size, the number of crystals within a segment is limited (typically 150-250 grains) and division into thinner segments was tested but rendered the porosity profiles exceedingly noisy. Centrifugation led to a cumulate layer with porosity differences in the cumulate of mostly $6.6 \pm 1.5 \mathrm{vol} \%$, the most compacted layers reaching porosities of 66-57 vol\% melt for the experiments on MOR-type basalt. The porosity differences for the one centrifuged experiment with lunar Fe-rich basalt (gxz137, Fig. 4b) are similar with 4.2 vol\%, albeit that this cumulate is more compacted with the top layer reaching $53 \mathrm{vol} \%$ melt (plagioclase floating). To make the profiles comparable, all porosity profiles in Fig. 5a were drawn such that compaction acts downward.

The relation between porosity reduction $\left(\varphi / \varphi_{0}\right)$ in the gravitationally most compacted layers of each experiment with effective pressure integrated over time expressed here as "applied pressure time" $(\Delta \rho \cdot h \cdot a \cdot t)$ is shown in Fig. 6 b. 
The experiments can be fit within error with a logarithmic function:

$\varphi / \varphi_{0}=-0.0582 \log (\Delta \rho \cdot h \cdot a \cdot t)+1.284$,

where $\varphi$ is the average porosity or melt fraction in the most compacted segment, $\varphi_{0}$ the initial porosity of the uncompacted plagioclase orthocumulate, $\Delta \rho$ the absolute value of the density contrast between melt and plagioclase, $h$ the cumulate height, $a$ acceleration and $t$ formation time. The compaction time for a plagioclase cumulate can then be calculated by solving Eq. (9) for time, scaling linearly for grain size $d$ (in $m$ in Eq. 10) using the experimental grain size of $29 \mu \mathrm{m}$, and using a $\varphi_{0}$ of 0.67 :

$t=\frac{3.83 \cdot 10^{26}}{10^{(\varphi \cdot 25.65)}} \cdot \frac{d}{\Delta \rho \cdot h \cdot a}$,

where $\varphi$ is the target porosity and $a$ gravitational acceleration, for Earth $9.81 \mathrm{~m} \cdot \mathrm{s}^{-2}$ and for the Moon $1.6 \mathrm{~m} \cdot \mathrm{s}^{-2}$.

For a 10-m-thick orthocumulate, a grain size of $5 \mathrm{~mm}$, and a typical density contrast of $50 \mathrm{~kg} \cdot \mathrm{m}^{-3}$, a compaction

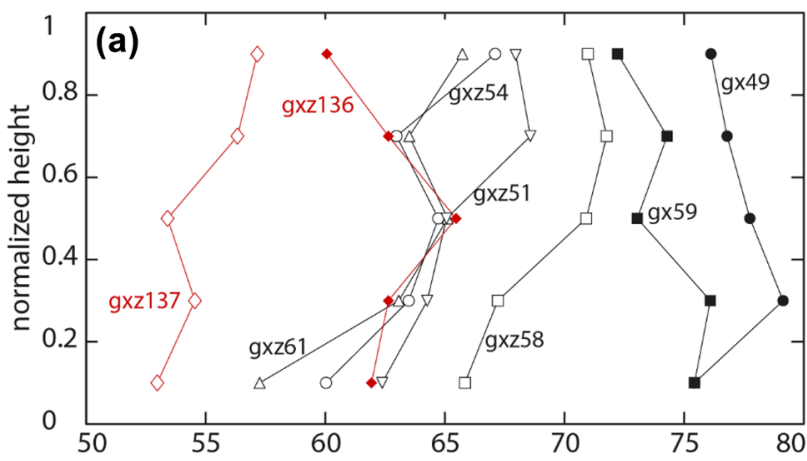

(b)

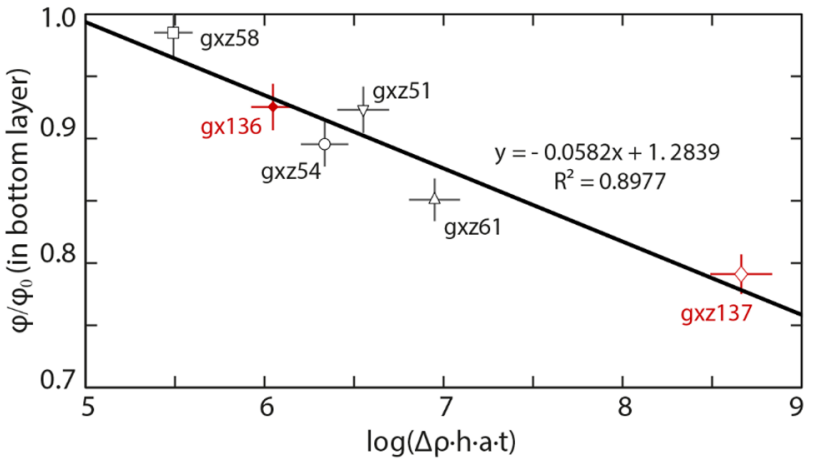

Fig. 6 a Porosity profiles of static (filled symbols) and centrifuged experiments (open symbols). Profiles are drawn such that compaction acts downward and the plagioclase floating experiments (gxz51, 61, 137 and gx136) are hence inverted. In red, the experiments with the lunar melt composition. b Porosity in the lower- or uppermost segments (for sinking or floating, respectively) versus the logarithm of the effective pressure integrated over time. $2 \sigma$-errors include an error of $2 \%$ in porosity, the uncertainty in $\mathrm{h}$ stemming from the uneven cumulate surface and the error in $\Delta \rho$ (see Table 3) time of $\sim 680 \mathrm{yrs}$ results for a final porosity of 0.4 (see Table 5). Figure 7 shows cumulate compaction timescales calculated from Eq. (10) for different grain sizes and cumulate heights.

\section{Discussion: application to lunar anorthosites}

To evaluate the compaction timescales of the lunar anorthosite floatation crust, Eq. (10) is used with the lunar gravity acceleration of $1.6 \mathrm{~m} \mathrm{~s}^{-2}$. Figure $7 \mathrm{c}$ shows that on a $\mathrm{km}$-scale, porosities down to 0.15 would be reached within 400,000 years for a 50-km-thick anorthosite (stippled lines give the estimated range of primordial lunar crust thickness of $35-75 \mathrm{~km}$ ). The interstitial melt would crystallize approximately $50 \%$ plagioclase, such that anorthosites with up to $90-93 \%$ plagioclase would form on 100,000 years timescales.

Cooling timescales for a lunar magma ocean are in the order of thousands of years until an (anorthositic) isolating lid forms, and then, cooling is modeled to slow down to millions of years for the remaining $\sim 100 \mathrm{~km}$ of magma ocean (Elkins-Tanton et al. 2011). If these latter timescales apply to the ultimate solidification of the anorthosites, then chemical compaction of a massive crust would not be timelimited but constrained by the effective melt escape threshold: chemical compaction at constant pressure and temperature occurs through recrystallization (i.e. a shape change) of the plagioclase and buoyancy-driven expulsion of the interstitial liquid, which leads to a decrease in porosity and hence permeability. At some critical threshold, thought to be a few percent of liquid (see discussion in Schmidt et al. 2012), interstitial liquid cannot escape anymore. A trapped liquid fraction of a few percent, again crystallizing in half to plagioclase, would be consistent with plagioclase contents of $96-99 \%$ in coherent lunar hand samples (Pernet-Fisher et al. 2019).

\section{Discussion: application to layered mafic intrusions}

The originally most popular mechanism (Bowen 1915; Darwin 1987; Wager et al. 1960; Wager and Brown 1968) to explain layering in LMIs, i.e. gravitational segregation, has become unpopular for plagioclase over the last decades because of the prediction that plagioclase would float (see e.g. Scoates, 2000, for discussion). In contrast, the mafic minerals olivine, opx and cpx are negatively buoyant in any tholeiitic magma at crustal pressures and settle.

Studies on more evolved layered intrusions such as SeptIles and Duluth indicate that early plagioclase compositions $\left(\mathrm{An}_{70}-\mathrm{An}_{60}\right)$ would already generally float (Chalokwu et al. 
Table 5 Melt and mineral compositions in layered mafic intrusions near the base of "layered," "banded" or "critical" macrounits where plagioclase appears as major cumulus mineral (data sources listed in Appendix III)

\begin{tabular}{|c|c|c|c|c|c|c|c|}
\hline \multirow[t]{2}{*}{ LMI } & \multirow{2}{*}{$\begin{array}{l}\text { Age } \\
{[\mathrm{Ma}]}\end{array}$} & \multirow{2}{*}{$\begin{array}{l}\text { Area } \\
{\left[\mathrm{km}^{2}\right]}\end{array}$} & \multirow{2}{*}{$\begin{array}{l}\text { Pressure* } \\
{[\mathrm{GPa}]}\end{array}$} & \multicolumn{2}{|c|}{$\begin{array}{l}X_{\mathrm{Mg}}^{\text {olivine }} X_{\mathrm{An}}^{\text {plag }} \\
\text { Max. values }\end{array}$} & \multicolumn{2}{|c|}{$\begin{array}{l}\mathrm{FeO}^{\text {melt }} \quad \rho^{\text {melt }} \\
\text { Proposed parent melt }\end{array}$} \\
\hline & & & & [molar] & [molar] & [wt $\%]$ & {$\left[\mathrm{kg} \cdot \mathrm{m}^{-3}\right]$} \\
\hline Bushveld & 2057 & 66,000 & 0.3 & $81-83$ & $78-80$ & $6.9-11.4$ & $2561-2696$ \\
\hline Stillwater & 2709 & 4400 & 0.3 & $81-84$ & 82 & $7.5-10.5$ & $2537-2712$ \\
\hline Great Dike & 2576 & 3800 & $?$ & 84 & 80 & 9.3 & 2637 \\
\hline Muskox & 1269 & 3500 & $\leq 0.1$ & $83-84$ & $>68 / ?$ & $9.8-10.9$ & $2696-2705$ \\
\hline Bjerkreim-Sokndal (N) & 920 & 230 & $0.57-0.75$ & $77-74$ & 50 & $12.4-13.7$ & $2696-2725$ \\
\hline Duluth (Partridge River) & 1099 & 4700 & 0.2 & 68 & 66 & $12.3 * *$ & 2740 \\
\hline Kiglapait & 1308 & 560 & 0.22 & 68 & 67 & $8.9-10.6^{* *}$ & $2638-2655$ \\
\hline Sept Iles & 565 & 5000 & $0.1-0.2$ & $72-68$ & $68-62$ & $14.5-15.1$ & 2759-2772 \\
\hline Skaergaard & 55 & 90 & 0.12 & 66 & 68 & $12.4-14.1$ & $2682-2733$ \\
\hline
\end{tabular}

*Estimated crystallization pressure used for density calculation.

**Note that the $X_{\mathrm{Mg}}$ of the proposed melt would lead to crystallization of a first olivine that is more magnesian than observed (a)

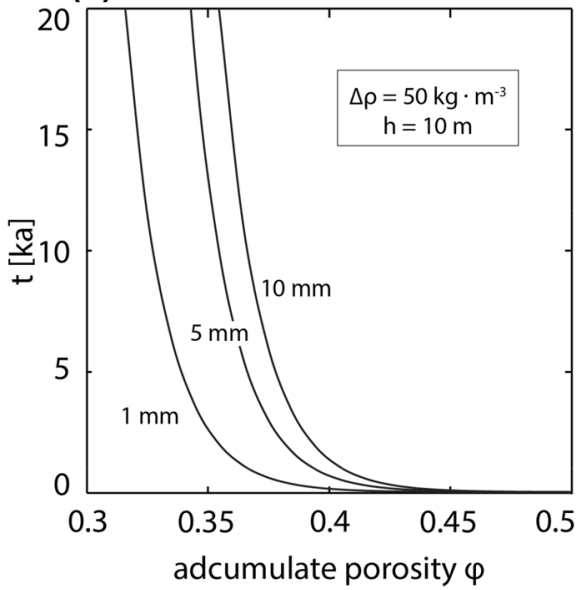

(b)

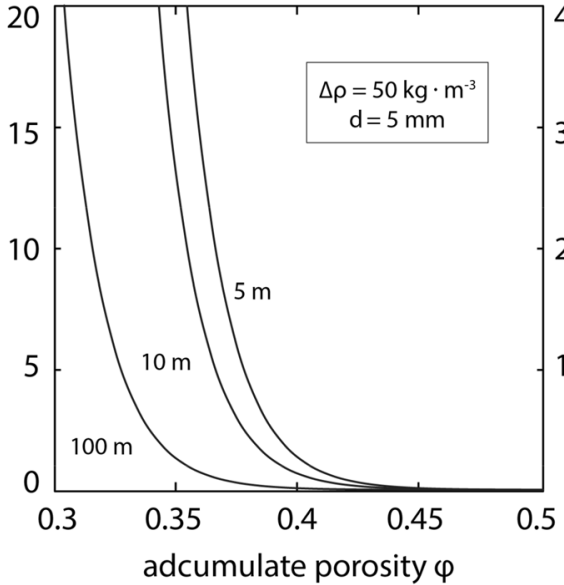

(c)

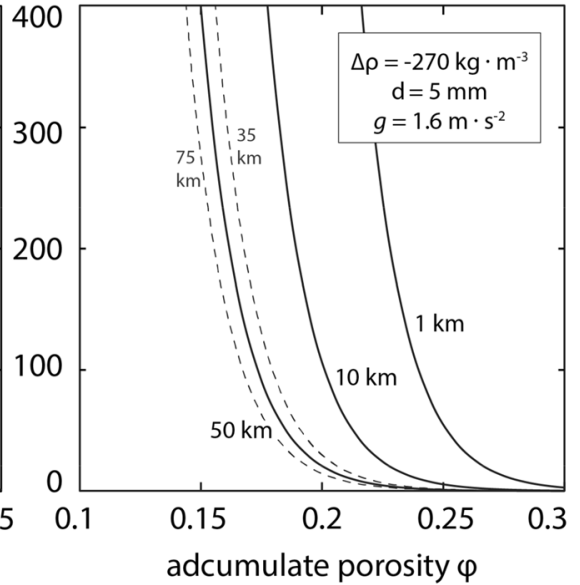

Fig. 7 Compaction timescales using parameters in the range of layered mafic intrusions a varying the grain size; $\mathbf{b}$ varying the cumulate height. c Compaction timescales for lunar anorthositic crust with varying thickness

1996; Namur et al. 2010, 2011), consistent with these intrusions developing roof layers of plagioclase. The Skaergaard intrusion also shows a felsic roof series; however, it is rather believed that plagioclase floatation did not essentially contribute to its formation but that the dominant process was cooling from the top (Irvine et al. 1998). Our experiments show that for the upper crustal pressures of most layered mafic intrusions and for a melt characteristic for the early crystallization of plagioclase in the more primitive LMIs, plagioclase should be negatively buoyant and would settle 
with the mafic minerals, albeit much slower. It has already been pointed out by Davies et al. (1980) that Bushveld and Skaergaard have principally different parent magmas and crystallization sequences. In fact, LMIs such as Bushveld, Stillwater, Great Dike or Muskox (Eales and Cawthorne 1996; Irvine 1977; Wilson et al. 1989) have parent melts that are less Fe-enriched and generally more Si-rich than those of, for example, Skaergaard, Sept-Iles or Bjerkreim-Sokndal (Norway) (McBirney 1996; Namur et al. 2015; Wilson et al. 1996). Hence, the former magmas are less dense but crystallize a more mafic, denser plagioclase $\left(\sim \mathrm{An}_{80}\right)$ in their "layered," "banded" or "critical" zones. In the following, we firstly investigate the question of whether plagioclase at the onset of its crystallization sinks or floats and secondly how layers of negatively buoyant plagioclase may compact within a sequence of mafic mineral layers.

\section{Buoyancy of plagioclase at the onset of its crystallization}

Application of our density results to layered mafic intrusions requires reconstructed liquid compositions, unfortunately a challenging enterprise. Often, proposed parent melt compositions stem from dikes or chilled margins, sometimes these are model compositions and some were tested experimentally. Mineral compositions impose some communalities on these mostly tholeiitic parent melts: olivine and pyroxene(s) crystallize with the first cumulate plagioclase, but are never truly primitive in composition. $\mathrm{X}_{\mathrm{Mg}}$ 's of olivine are 0.84-0.81 in the LMIs with the least evolved parental melts (Bushveld, Stillwater, Great Dike, Muskox; Table 5), while in several smaller and mostly younger layered mafic intrusions (Skaergaard, Sept Iles, Bjerkreim-Sokndal (Norway), Duluth) early plagioclase coexists with olivine (or pyroxene) of $X_{\mathrm{Mg}}$ 0.74-0.55. In the former group, plagioclase commences to crystallize with $X_{\mathrm{An}} \sim 82-78$, while the latter have rather $X_{\mathrm{An}} \sim 68-50$. The parent liquids at plagioclase saturation are hence mildly to strongly evolved from primitive mantle melts, which at the reigning tholeiitic Fe-enrichment trend leads to proposed $\mathrm{FeO}$ contents of about 7-11 wt\% (all $\mathrm{Fe}$ as $\mathrm{FeO}$ ) and liquid $X_{\mathrm{Mg}}$ 's of $0.52-0.74$ for Bushveld, Stillwater, Great Dike and Muskox, while 12.5-15 wt\% FeO and liquid $X_{\mathrm{Mg}}$ 's of $0.38-48$ are proposed for Skaergaard, Sept Iles and Bjerkreim-Sokndal (Norway). Note that for the former group most proposed parent melts have 51-55 wt $\%$ $\mathrm{SiO}_{2}$, in accordance with the dominance of opx as pyroxene, while for the latter group [and for Kiglapait (Morse 1996) and Duluth (Chalokwu et al. 1993a, b)] most proposed parent melts have $<50 \mathrm{wt} \% \mathrm{SiO}_{2}$ and crystallize none or subordinate opx or inverted pigeonite (Fig. 8).

The density calculations then reveal a consistent picture: At the characteristic pressures of 1-3 kbar, the (moderately) high-Si melts with 7-11 wt $\% \mathrm{FeO}$ would have negatively buoyant $\mathrm{An}_{80-70}$, while those with $\mathrm{SiO}_{2}<50 \mathrm{wt} \%$ and $\mathrm{FeO}>12.5-15 \mathrm{wt} \%$ would float $\mathrm{An}_{68-50}$. The differences in compositional parameters of the proposed parent melts to the layered series, albeit with little influence on density, are also mirrored in $0.3-0.8 \mathrm{wt} \% \mathrm{TiO}_{2}$ and $0.05-0.2 \mathrm{wt} \% \mathrm{P}_{2} \mathrm{O}_{5}$ for Bushveld, Stillwater, the Great Dike and Muskox, while those for Skaergaard, Sept Iles and Bjerkreim-Sokndal have typically $2-4 \mathrm{wt} \% \mathrm{TiO}_{2}$ and $0.3-0.8 \mathrm{wt} \% \mathrm{P}_{2} \mathrm{O}_{5}$, testifying for a somewhat more alkaline affinity of the latter.

It is far beyond the scope of this contribution to evaluate proposed parent liquid compositions, which are either derived from marginal facies, chilled (margins of) dikes and sills, recalculated and modeled from phase equilibria or determined experimentally. As a disclaimer, the above density considerations are for the lowermost mafic layered or banded or cryptic macrounits (mostly underlain by ultramafic macrounits) and do not apply anymore for the more massive main units and anything further differentiated. Nevertheless, from the above, it becomes clear that notable units such as the UG1 in Bushveld (Nex 2004) or the two mighty anorthosites in the Middle Banded Series of Stillwater (McCallum 1996) can form by gravitation alone. 


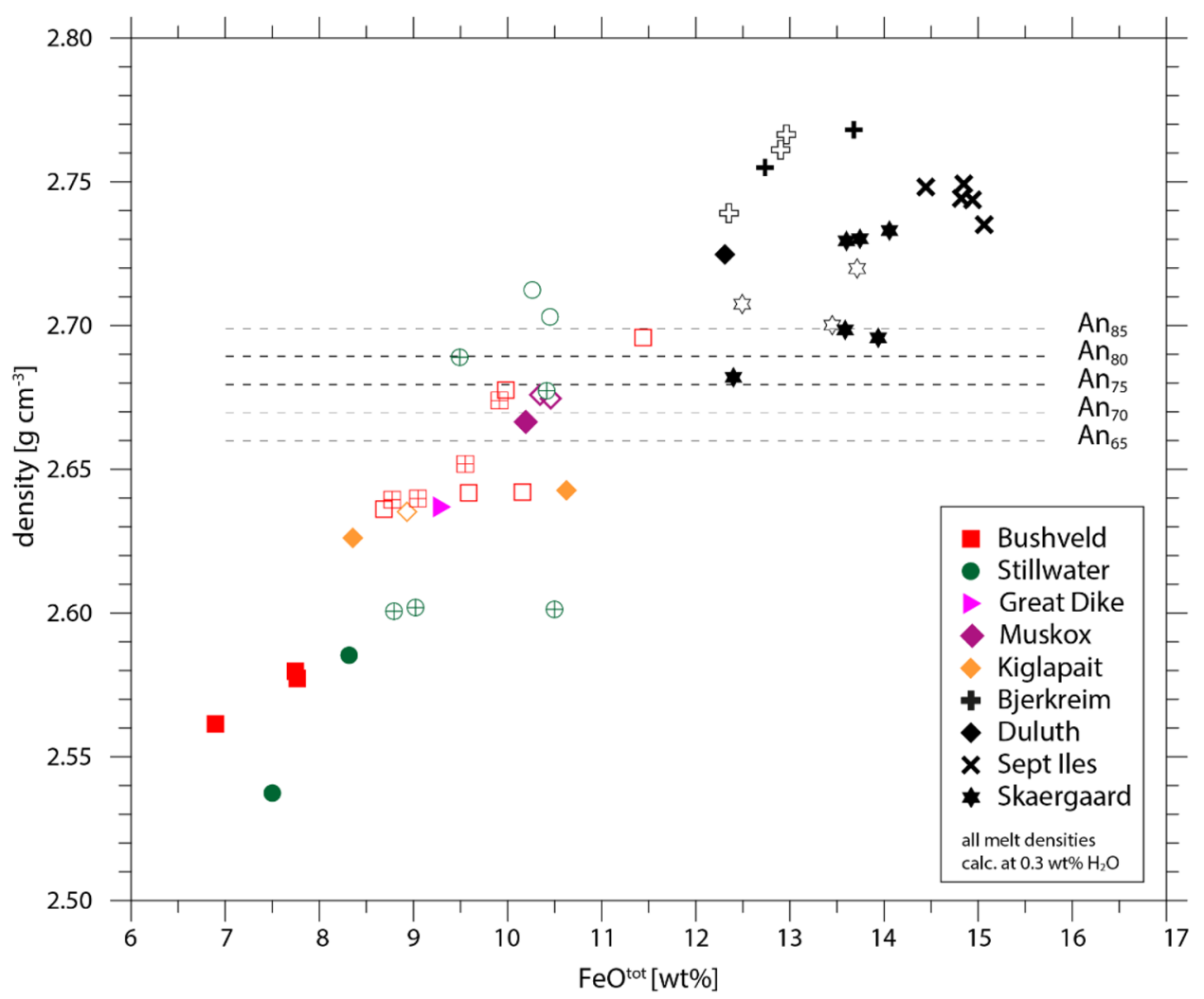

Fig. 8 Densities of proposed parent melts (at their estimated crystallization pressure, Table 5) and plagioclase of $\mathrm{An}_{85}-\mathrm{An}_{65}$ (at 0.3 $\mathrm{GPa}, 1150{ }^{\circ} \mathrm{C}$ ) as relevant for plagioclase crystallization in their various layered, banded or cryptic zones. The high-Si melts (Bushveld, Stillwater, Great Dike, Muskox) have generally negatively buoyant plagioclase of $\mathrm{An}_{82-78}$, the somewhat alkaline or more evolved LMIs (Skaergaard, Sept Iles, Bjerkreim-Sokndal (Norway), and Duluth) crystallize buoyant plagioclase of $\mathrm{An}_{68-50}$. Note that the proposed

\section{Compaction of plagioclase and formation of anorthosite layers}

Plagioclase layers in the critical zone of layered intrusions are typically meter thick and, as shown above, would not compact much on its own over the available time scales, which are limited by cooling induced crystallization of the interstitial melt. Nevertheless, it is unlikely that a single layer or a single sequence of modal layers compacts on its own. Typically, repetitive layer sequences are thought to deposit fast, relative to cooling times of layered mafic intrusions, and most importantly, new layers form while the parent melt of Kiglapait would be in equilibrium with $\mathrm{Fo}_{85}$, while the highest observed $X_{\mathrm{Mg}}$ in olivine is 0.68 (for Duluth $\mathrm{Fo}_{81}$ and observed $X_{\mathrm{Mg}}{ }^{\text {olivine }}=0.68$ ); adequate modification of the Kiglapait melt would probably lead to $\geq 14 \mathrm{wt} \% \mathrm{FeO}$ and a density $>2690 \mathrm{~kg} \mathrm{~m}^{3}$, to be compared to $\mathrm{An}_{67}$. Symbol shape coded for intrusion, open symbols: natural rock compositions, crossed symbols: model melts, full symbols: experimental melts. For references, see Appendix III

melt fraction in the lower layer(s) remains in a liquid state (e.g. Nex 2004). The effectiveness of the compaction process will depend on deposition vs. cooling rate; i.e. whether cumulates may compact to the connectivity threshold of the interstitial melt depends on the time and overload available for compaction. As an illustration, Fig. 9 shows the porosity of a 1-m-thick plagioclase layer as developing with time under an overload of 1-100 m mafic mineral cumulates. This overload effectively reduces the final porosity by $0.04-0.12$ to $0.35-0.30$ after a few thousand years, increasing the total plagioclase fraction after crystallization of the interstitial melt to a maximum $80-85 \%$ (Fig. 9). 


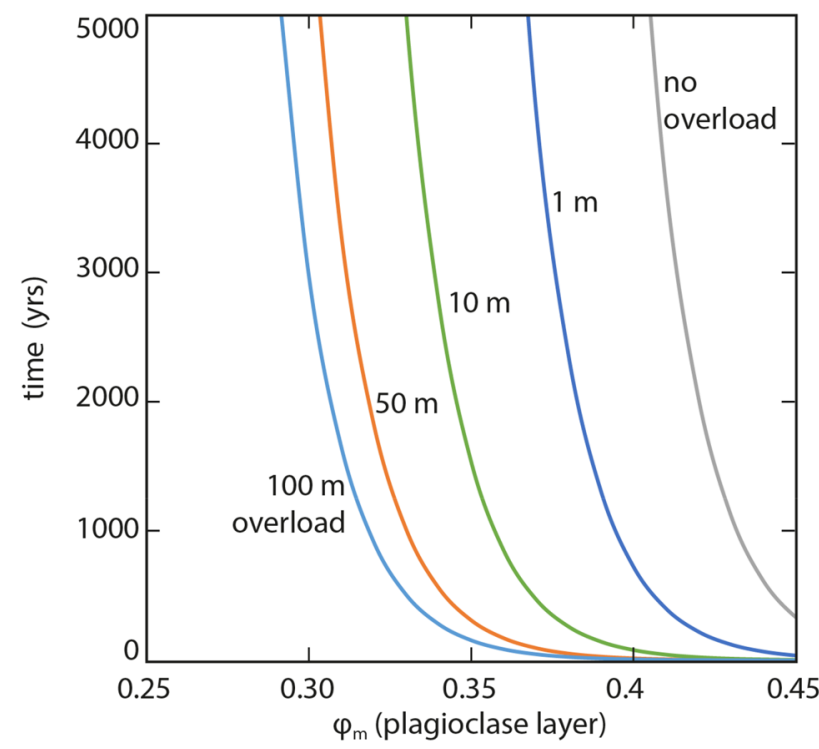

Fig. 9 Porosity of a $1 \mathrm{~m}$ plagioclase cumulate layer as a function of time without overload and with $1,10,50$ and $100 \mathrm{~m}$ overload of mafic minerals. Note that approximately half of the interstitial melt in the resulting porosity will crystallize to plagioclase, yielding plagioclase fractions of at most $0.80-0.85$ on a timescale of kyrs

\section{Conclusion}

This study confirms experimentally that gravitational plagioclase settling is feasible as envisaged by e.g. Wager and Brown (1968). In fact, early plagioclase in tholeiitic suites is negatively buoyant at upper crustal pressures, rendering the demise of gravitational plagioclase settling premature. Whether positively or negatively buoyant, for plagioclase alone, hundreds-of-meter-thick cumulate piles are necessary to obtain plagioclase contents of $80-90 \%$ through compaction, values observed in many anorthosites. When plagioclase is negatively buoyant, these cumulate piles may be constituted by any mineral (e.g. chromite, olivine, opx, cpx), as the force resulting from their (larger) density contrast accumulates and acts throughout the entire mushy crystal pile contributing to compaction-as long as the interstitial melt does not freeze.

Gravitational segregation versus, e.g., in situ crystallization and double diffusive convection or other processes producing plagioclase cumulates must be discussed individually for each magma chamber or layered mafic intrusion. As long as the estimated density difference agrees to the observed buoyancy, we suggest applying Ockham's razor in favor of gravitational segregation.

This work presents novel experimental data for the calculation of plagioclase buoyancy and compaction in magmatic environments dominated by plagioclase. Combined with the two companion studies on olivine (Schmidt et al. 2012) and chromite (Manoochehri and Schmidt 2014), the compaction velocities of three important minerals of mafic intrusions are now experimentally determined. Olivine and pyroxene(s), likely to behave similar to olivine, and plagioclase are the most important rock-forming minerals of basaltic magmatism, tracing information about major processes forming a vast amount of magmatism on Earth (e.g. MORB's, LMI), on the Moon, and on any rocky planet or planetesimal that experienced a magma ocean stage. The same few minerals form the majority of the low pressure phase assemblages of primitive basaltic compositions. Understanding and quantifying their physical behavior in large magma chambers seems a prerequisite to understand fractionation with all its consequences.

\section{Appendix}

\section{Al: Chemical compositions of analysed phases from the reported experiments}

See Table 6 


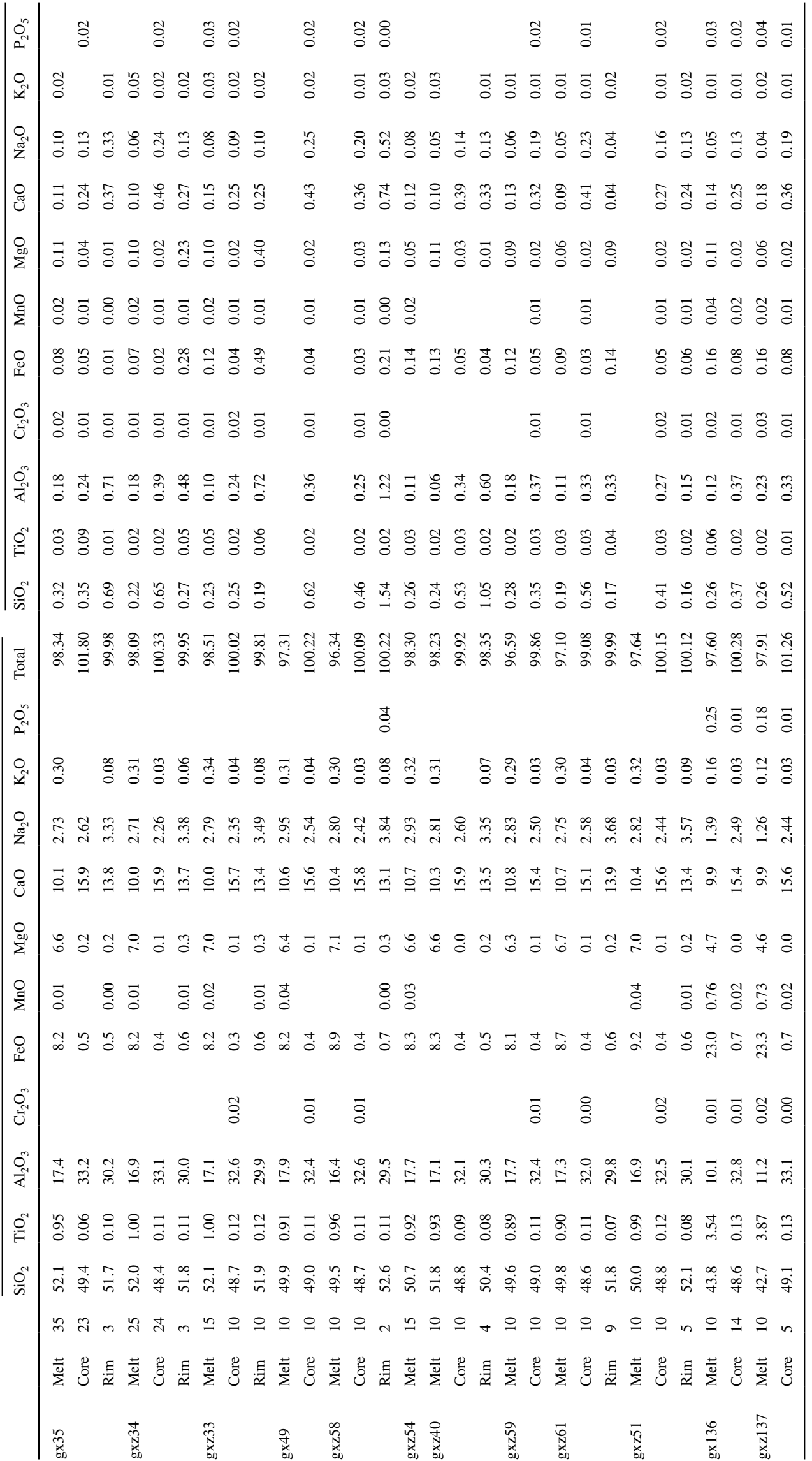




\section{All: Additional experiments mentioned in the text}

See Fig. 10.
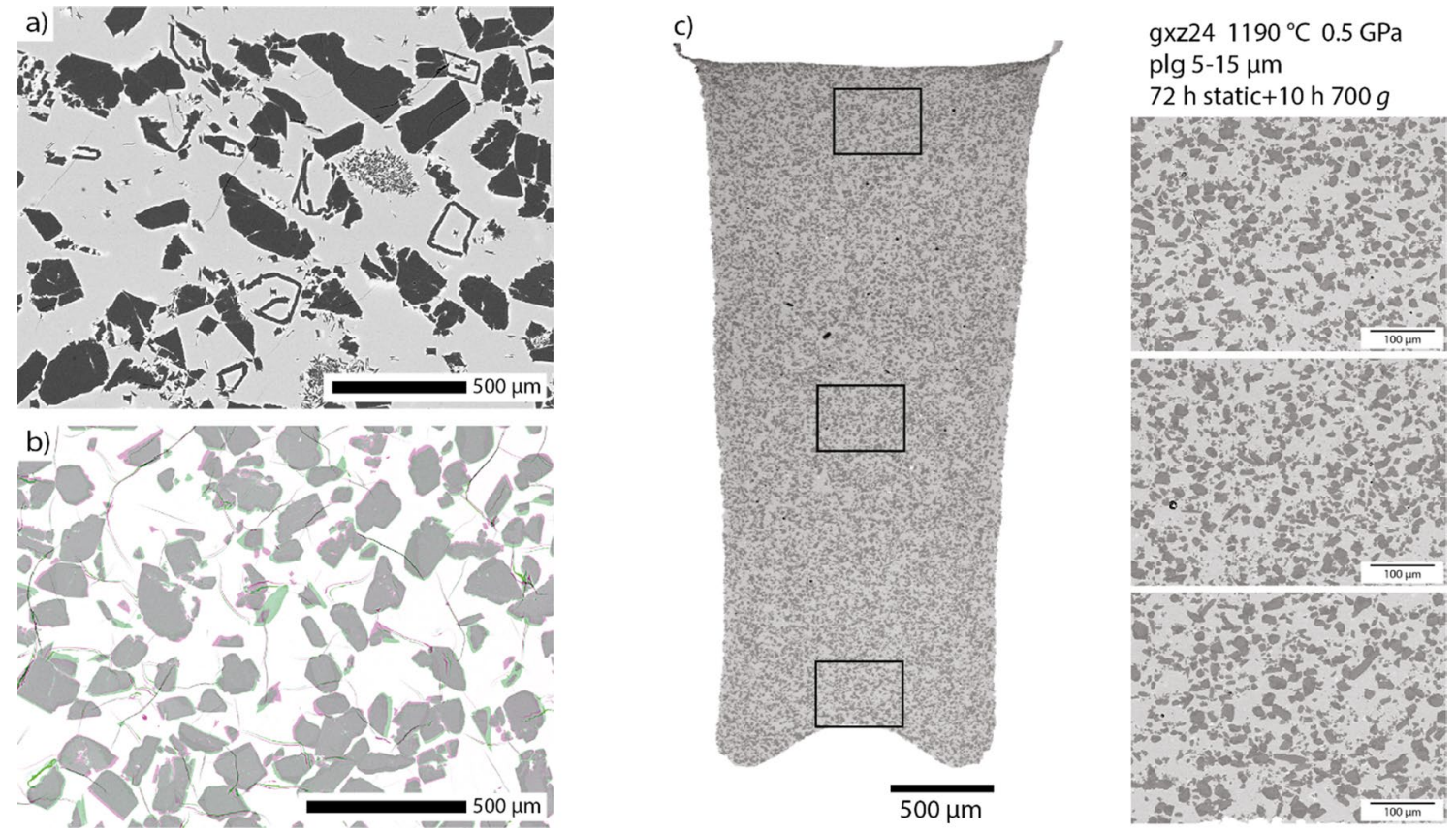

Fig. 10 a gx 135: experiment where the $X_{\mathrm{An}}$ of the plagioclase seeds were lower than the equilibrium value. The $\mathrm{An}_{77}$ seeds are overgrown by rims of $\mathrm{An}_{82}$ being in equilibrium with this melt, the seeds (cores) dissolve in this case. b gxz53: experiment that was analysed twice by image analysis as described in the section "Image analysis". Red areas are plagioclase grains in the first polishing, green areas grains

after the second polishing, they appear grey where the overlap (area differences are $<1$ area\%). c gxz24: experiment with plagioclase seeds smaller than $15 \mu \mathrm{m}$ resulted in little movement of the grains when centrifuging for $10 \mathrm{~h}$ at $700 \mathrm{~g}$, a centrifugation period largely sufficient for full settling and the beginning of compaction at the subsequently used plagioclase grain size of $\sim 30 \mu \mathrm{m}$

\section{Alll: Experimental, natural, and modelled LMI melt compositions (used for densities in Fig. 8)}

See Table 7. 


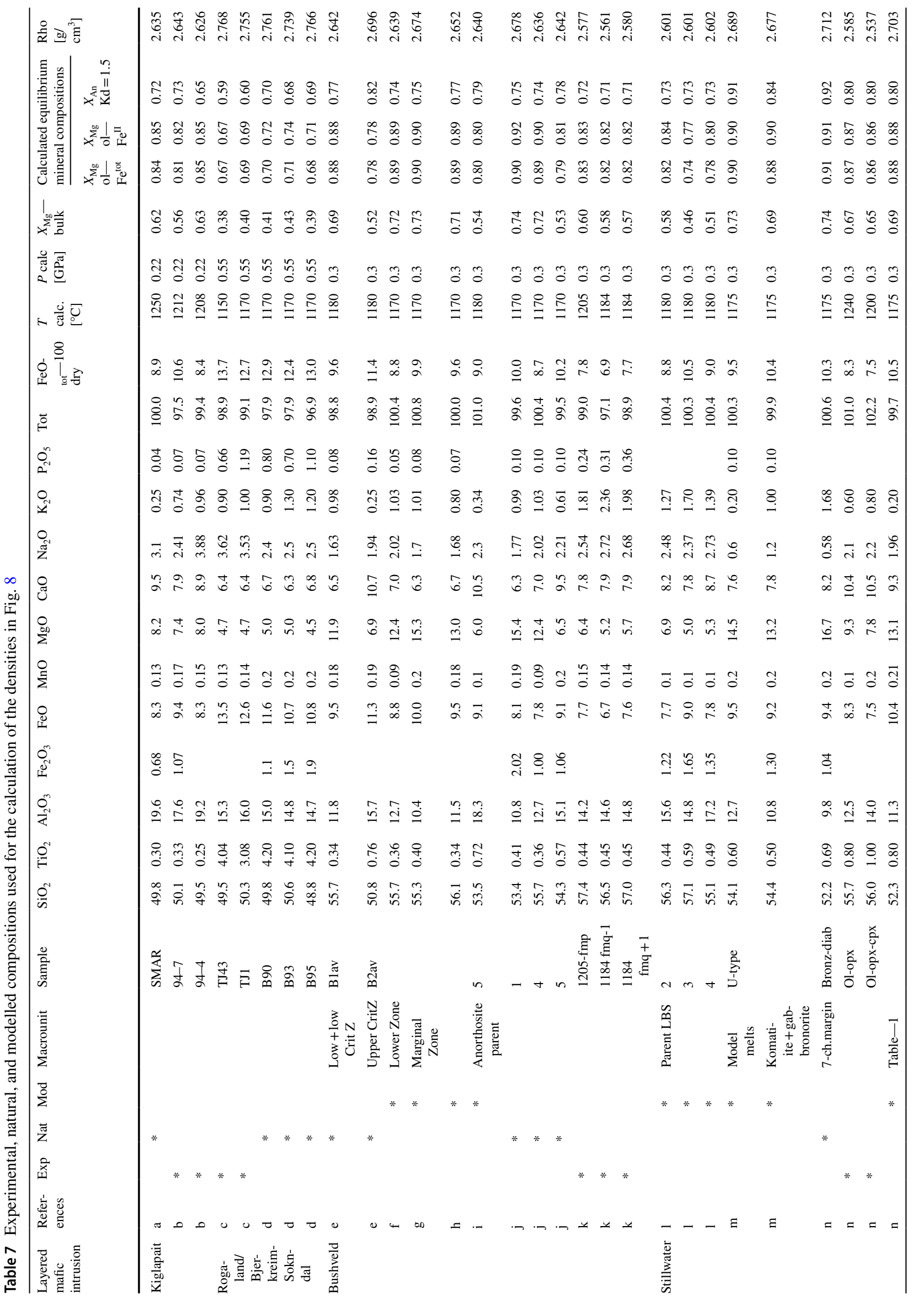




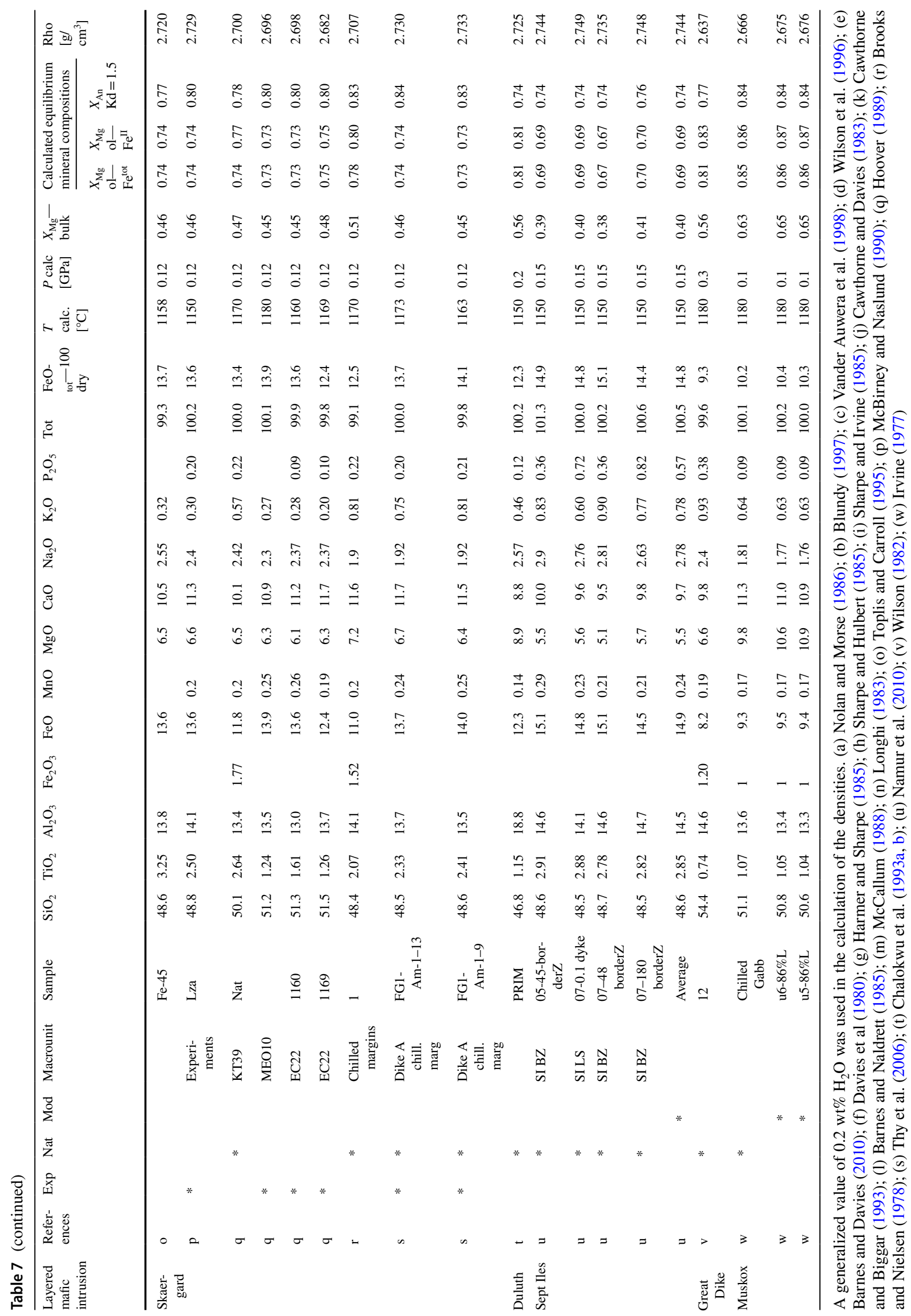




\section{AIV: Raman spectra}

See Fig. 11.

Fig. 11 Raman spectra of two representative samples (gxz40, gxz54). These are compared with three synthetic tholeiitic standard glasses, with 1,2 and 3 wt $\%$ water (Trubowitz 2018). The water peaks [ca. $3500+$, Raman shift $\left.\left(\mathrm{cm}^{-1}\right)\right]$ in the right part of the chart are not (gxz40) and almost not visible (gxz54), quantification is not possible, qualitatively we are confident, that even in the longest runtime experiment the water content is below $0.5 \mathrm{wt} \%$

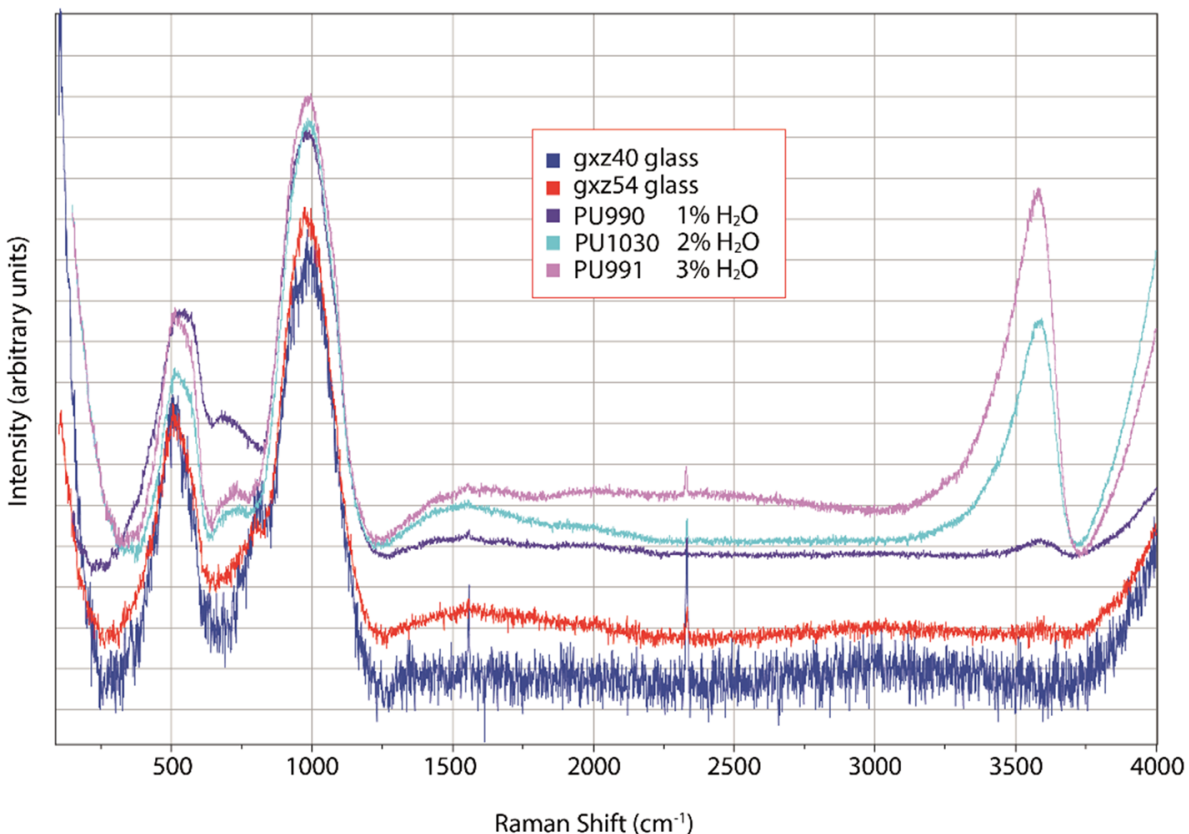

Acknowledgements This work was supported by generous funding of ETH. We want to thank P. Ulmer, C. Liebske for experimental issues, T. Good and A. Huber for keeping the centrifuge running and B. Charlier and $\mathrm{J}$. vanTongeren for discussions on layered mafic intrusions.

Funding Open access funding provided by Swiss Federal Institute of Technology Zurich.

Open Access This article is licensed under a Creative Commons Attribution 4.0 International License, which permits use, sharing, adaptation, distribution and reproduction in any medium or format, as long as you give appropriate credit to the original author(s) and the source, provide a link to the Creative Commons licence, and indicate if changes were made. The images or other third party material in this article are included in the article's Creative Commons licence, unless indicated otherwise in a credit line to the material. If material is not included in the article's Creative Commons licence and your intended use is not permitted by statutory regulation or exceeds the permitted use, you will need to obtain permission directly from the copyright holder. To view a copy of this licence, visit http://creativecommons.org/licenses/by/4.0/.

\section{References}

Abers GA, Hacker BR (2016) A MATLAB toolbox and Excel workbook for calculating the densities, seismic wave speeds, and major element composition of minerals and rocks at pressure and temperature. Geochem Geophy Geosy 17:616-624

Aigner-Torres M, Blundy J, Ulmer P, Pettke T (2007) Laser ablation ICPMS study of trace element partitioning between plagioclase and basaltic melts: an experimental approach. Contrib Miner Petr 153:647-667

Angel RJ (2004) Equations of state of plagioclase feldspars. Contrib Miner Petr 146:506-512

Ashwal LD (1993) Anorthosites. Springer Verlag, Berlin

Ashwal LD, Bybee GM (2017) Crustal evolution and the temporality of anorthosites. Earth-Sci Rev 173:307-330

Baldock TE, Tomkins MR, Nielsen P, Hughes MG (2004) Settling velocity of sediments at high concentrations. Coast Eng 51:91-100

Barnes SJ, Naldrett AJ, Gorton MP (1985) The origin of the fractionation of platinum-group elements in terrestrial magmas. Chem Geol 53:303-323

Barnes SJ, Maier WD, Curl EA (2010) Composition of the marginal rocks and sills of the Rustenburg Layered Suite, Bushveld Complex, South Africa: implications for the formation of the platinum-group element deposits. Econ Geol 105:1491-1511

Bina CR, Helffrich GR (1992) Calculation of elastic properties from thermodynamic equation of state principles. Annu Rev Earth Plant Sc 20:527-552

Blundy J (1997) Experimental study of a Kiglapait marginal rock and implications for trace element partitioning in layered intrusions. Chem Geol 141:73-92

Bohlen SR, Boettcher AL (1980) The quartz $\leftrightarrows$ coesite transformation: a precise determination and the effect of other components. J Geophys Res 87:7073-7078

Bose K, Ganguly J (1995) Quartz-coesite transition revisited - reversed experimental-determination at $500-1200{ }^{\circ} \mathrm{C}$ and retrieved thermochemical properties. Am Miner 80:231-238

Bottinga Y, Weill DF (1970) Densities of liquid silicate systems calculated from partial molar volumes of oxide components. Am J Sci 269:169-182 
Bowen NL (1915) Crystallization-differentiation in silicate liquids. Am J Sci 230:175-191

Bowen NL (1917) The problem of the anorthosites. J Geol 25:209-243

Brooks CK, Nielsen TFD (1978) Early stages in the differentiation of the Skaergaard magma as revealed by a closely related suite of dike rocks. Lithos 1:1-14

Cabane H, Laporte D, Provost A (2005) An experimental study of Ostwald ripening of olivine and plagioclase in silicate melts: implications for the growth and size of crystals in magmas. Contrib Miner Pet 150:37-53

Campbell IH, Roeder PL, Dixon JM (1978) Plagioclase buoyancy in basaltic liquids as determined with a centrifuge furnace. Contrib Mineral Pet 76:369-377

Cawthorn RG, Biggar GM (1993) Crystallization of titaniferous chromite, magnesian ilmenite and armalcolite in tholeiitic suites in the Karoo Igneous Province. Contrib Miner Pet 114:221-235

Cawthorn RG, Davies G (1983) Experimental data at 3 kbars pressure on parental magma to the Bushveld Complex. Contrib Miner Pet 83:128-135

Chalokwu CI, Grant NK, Ariskin AA, Barmina GS (1993a) Simulation of primary phase relations and mineral compositions in the Partridge River intrusion, Duluth Complex, Minnesota: implications for the parent magma composition. Contrib Miner Pet 114:539-549

Chalokwu CI, Grant NK, Ariskin AA, Barmina GS (1993b) Simulation of primary phase relations and mineral compositions in the Partridge River intrusion, Duluth Complex, Minnesota: implications for the parent magma composition. Contrib Miner Pet 114:539-549

Chalokwu CI, Ariskin AA, Koptev-Dvornikov EV (1996) Magma dynamics at the base of an evolving mafic magma chamber: Incompatible element evidence from the Partridge River intrusion, Duluth Complex, Minnesota, USA. Geochim Cosmochim Acta 60:4997-5011

Clark SP (1959) Effect of Pressure on the melting points of eight alkali halides. J Chem Phys 31:1526-1531

Connolly JAD (1990) Calculation of multivariable phase diagrams: an algorithm based on generalized thermodynamics. Am J Sci 290:666-718

Connolly JAD (2005) Computation of phase equilibria by linear programming: a tool for geodynamic modeling and its application to subduction zone decarbonation. Earth Planet Sci Lett 236:524-541

Corlett M, Eberhard E (1967) Das Material für chemische und physikalische Untersuchungen an Plagioklasen. Schweiz Miner Petrog Mitt 47:303-316

Darwin C (1987) Charles Darwin's notebooks, 1836-1844: geology, transmutation of species, metaphysical enquiries. Cornell University Press

Davies G, Cawthorn RG, Barton JM, Morton M (1980) Parental magma to the Bushveld Complex. Nature 287:33-35

Eales HV, Cawthorn RG (1996) The Bushveld complex. Dev Pet $15: 181-229$

Elkins-Tanton LT, Burgess S, Yin QZ (2011) The lunar magma ocean: Reconciling the solidification process with lunar petrology and geochronology. Earth Planet Sci Lett 304:326-336

Faroughi SA, Huber C (2015) Unifying the relative hindered velocity in suspensions and emulsions of nondeformable particles. Geophys Res Lett 42:53-59

Faul UH, Scott D (2006) Grain growth in partially molten olivine aggregates. Contrib Miner Pet 151:101-111

Fei Y (1995) Thermal expansion. In: Mineral physics and crystallography: a handbook of physical constants. American Geophysical Union

Giordano D, Russell JK, Dingwell DB (2008) Viscosity of magmatic liquids: a model. Earth Planet Sci Lett 271:123-134
Green EC, White RW, Diener JF, Powell R, Holland TJ, Palin RM (2016) Activity-composition relations for the calculation of partial melting equilibria in metabasic rocks. J Metamorph Geol 34:845-869

Grove TL, Baker MB, Kinzler RJ (1984) Coupled CaAl-NaSi diffusion in plagioclase feldspar: Experiments and applications to cooling rate speedometry. Geochim Cosmochim Acta 48:2113-2121

Harmer RE, Sharpe MR (1985) Field relations and strontium isotope systematics of the marginal rocks of the eastern Bushveld Complex. Econ Geol 80:813-837

Hernlund J, Leinenweber K, Locke D, Tyburczy JA (2006) A numerical model for steady-state temperature distributions in solid-medium high-pressure cell assemblies. Am Miner 91:295-305

Holland TJB, Powell RTJB (1998) An internally consistent thermodynamic data set for phases of petrological interest. J Metamorph Geol 16:309-343

Holland TJ, Powell R (2011) An improved and extended internally consistent thermodynamic dataset for phases of petrological interest, involving a new equation of state for solids. J Metamorph Geol 29:333-383

Hoover JD (1989) The chilled marginal gabbro and other contact rocks of the Skaergaard intrusion. J Pet 30:441-476

Irvine TN (1969) Crystallization sequences in the Muskox Intrusion and other intrusions. In: The J. Willemse commemorative volume containing the papers presented at the symposium on the Bushveld igneous complex and other layered intrusions published by the Geological Society of South Africa Special Publication 1, 1970 Symposium on the Bushveld Igneous Complex and other Layered Intrusions

Irvine TN (1970) Heat transfer during solidification of layered intrusions. I. Sheets and sills. Can J Earth Sci 7:1031-1061

Irvine TN (1977) Origin of chromitite layers in the Muskox intrusion and other stratiform intrusions: a new interpretation. Geology $5: 273-277$

Irvine TN (1982) Terminology for layered intrusions. J Petrol 23:127-162

Irvine TN, Andersen JCO, Brooks CK (1998) Included blocks (and blocks within blocks) in the Skaergaard intrusion: Geologic relations and the origins of rhythmic modally graded layers. GSA Bull 110:1398-1447

Jagoutz O, Müntener O, Schmidt MW, Burg JP (2011) The roles of flux-and decompression melting and their respective fractionation lines for continental crust formation: Evidence from the Kohistan arc. Earth Planet Sci Lett 303:25-36

Joseph DD, Fortes A, Lundgren TS, Singh P (1986) Nonlinear mechanics of fluidization of spheres, cylinders and disks in water. Phys Fluids 30:101-122

Kadik AA, Lebedev YB (1995) Separating the melt from the crystalline matrix: Simulation in a centrifuge. In: Lunar and Planetary Science Conference Vol. 26

Khazan Y (2010) Melt segregation and matrix compaction: the mush continuity equation, compaction/segregation time, implications. Geophys J Int 183:601-610

Kress VC, Carmichael IS (1991) The compressibility of silicate liquids containing $\mathrm{Fe}_{2} \mathrm{O}_{3}$ and the effect of composition, temperature, oxygen fugacity and pressure on their redox states. Contrib Miner Pet 108:82-92

Kushiro I, Fujii T (1977) Flotation of plagioclase in magma at high pressures and its bearing on the origin of anorthosite. Proc Jpn Acad 58:262-266

Lange RA, Carmichael IS (1987) Densities of $\mathrm{Na}_{2} \mathrm{O}-\mathrm{K}_{2} \mathrm{O}-\mathrm{CaO}-\mathrm{MgO}-$ $\mathrm{FeO}-\mathrm{Fe}_{2} \mathrm{O}_{3}-\mathrm{Al}_{2} \mathrm{O}_{3}-\mathrm{TiO}_{2}-\mathrm{SiO}_{2}$ liquids: new measurements and derived partial molar properties. Geochim Cosmochim Acta 51:2931-2946

Lange RA, Carmichael IS (1990) Thermodynamic properties of silicate liquids with emphasis on density, thermal expansion and 
compressibility. Modern methods of igneous petrology: understanding magmatic processes. Rev Mineral Geochem 24:25-64

Le Losq C, Neuville DR, Moretti R, Roux J (2012) Determination of water content in silicate glasses using Raman spectrometry: Implications for the study of explosive volcanism. Am Miner 97:779-790

Lesher CE, Walker D (1988) Cumulate maturation and melt migration in a temperature gradient. J Geophys Res-Solid 93:10295-10311

Longhi J, Wooden JL, Coppinger KD (1983) The petrology of highMG dikes from the Beartooth Mountains, Montana: a search for the parent magma of the Stillwater Complex. J Geophys Res Solid Earth 88:B53-69

Manoochehri S, Schmidt MW (2014) Settling and compaction of chromite cumulates employing a centrifuging piston cylinder and application to layered mafic intrusions. Contrib Miner Pet 168:1091

McBirney AR (1996) The Skaergaard intrusion. Dev Pet 15:147-180

McBirney AR, Naslund HR (1990) The differentiation of the Skaergaard intrusion. Contrib Miner Pet 104:235-240

McCallum IS (1988) Evidence for crustal recycling during the Archean: The parental magmas of the Stillwater Complex. In: Workshop on the Growth of Continental Crust, p. 92

McCallum IS (1996) The stillwater complex. Dev Pet 15:441-483

McKenzie DP (1987) The compaction of igneous and sedimentary rocks. J Geol Soc Lond 144:299-307

McNown JS, Malaika J (1950) Effects of particle shape on settling velocity at low Reynolds numbers. Eos Trans Am Geophys Union 31:74-82

Morse SA (1996) Kiglapait mineralogy III: olivine compositions and Rayleigh fractionation models. J Pet 37:1037-1061

Namur O, Charlier B, Toplis MJ, Higgins MD, Liégeois JP, Vander Auwera J (2010) Crystallization sequence and magma chamber processes in the ferrobasaltic Sept Iles layered intrusion, Canada. J Pet 51:1203-1236

Namur O, Charlier B, Pirard C, Hermann J, Liégeois JP, Auwera JV (2011) Anorthosite formation by plagioclase flotation in ferrobasalt and implications for the lunar crust. Geochim Cosmochim Acta 75:4998-5018

Namur O, Abily B, Boudreau AE, Blanchette F, Bush JW, Ceuleneer G, Charlier B, Donaldson CH, Duchesne JC, Higgins MD, Morata D (2015) Igneous layering in basaltic magma chambers. Layered intrusions. Springer, Dordrecht, pp 75-152

Newton RC, Charlu TV, Kleppa OJ (1980) Thermochemistry of the high structural state plagioclases. Geochim Cosmochim Acta 44:933-941

Nex PA (2004) Formation of bifurcating chromitite layers of the UG1 in the Bushveld Igneous Complex, an analogy with sand volcanoes. J Geol Soc Lond 161:903-909

Nolan KM, Morse SA (1986) Marginal rocks resembling the estimated bulk composition of the Kiglapait intrusion. Geochim Cosmochim Acta 50:2381-2386

Ochs FA III, Lange RA (1997) The partial molar volume, thermal expansivity, and compressibility of $\mathrm{H}_{2} \mathrm{O}$ in $\mathrm{NaAlSi}_{3} \mathrm{O}_{8}$ liquid: new measurements and an internally consistent model. Contrib Miner Pet 129:155-165

Ochs FA, Lange RA (1999) The density of hydrous magmatic liquids. Science 283:1314-1317

Ostwald W (1900) Über die vermeintliche Isomerie des roten und gelben Quecksilberoxyds und die Oberflächenspannung fester Körper. Z Phys Chem 34:495-503

Pernet-Fisher JF, Deloule E, Joy KH (2019) Evidence of chemical heterogeneity within lunar anorthosite parental magmas. Geochim Cosmochim Acta 266:109-130

Prewitt CT, Sueno S, Papike JJ (1976) The crystal structures of high albite and monalbite at high temperatures. Am Miner 61:1213-1225
Richardson JF, Zaki WN (1954) The sedimentation of a suspension of uniform spheres under conditions of viscous flow. Chem Eng Sci 3:65-73

Roeder PL, Dixon JM (1977) A centrifuge furnace for separating phases at high temperature in experimental petrology. Can J Earth Sci 14:1077-1084

Rowe PN (1987) A convenient empirical equation for estimation of the Richardson-Zaki exponent. Chem Eng Sci 42:2795-2796

Schmidt MW, Connolly JAD, Gunther D, Bogaerts M (2006) Element partitioning: the role of melt structure and composition. Science 312:1646-1650

Schmidt MW, Forien M, Solferino G, Bagdassarov N (2012) Settling and compaction of olivine in basaltic magmas: an experimental study on the time scales of cumulate formation. Contrib Miner Petr 164:959-976

Schneider CA, Rasband WS, Eliceiri KW (2012) NIH Image to ImageJ: 25 years of image analysis. Nat Methods 9:671

Schwindinger KR (1999) Particle dynamics and aggregation of crystals in a magma chamber with application to Kilauea Iki olivines. J Volcanol Geoth Res 88:209-238

Scoates JS (2000) The plagioclase-magma density paradox re-examined and the crystallization of Proterozoic anorthosites. J Pet 41:627-649

Sharpe MR, Hulbert LJ (1985) Ultramafic sills beneath the eastern Bushveld Complex; mobilized suspensions of early lower zone cumulates in a parental magma with boninitic affinities. Econ Geol 80:849-871

Sisson TW, Grove TL (1993) Experimental investigations of the role of $\mathrm{H}_{2} \mathrm{O}$ in calc-alkaline differentiation and subduction zone magmatism. Contrib Miner Pet 113:143-166

Smith JV, Anderson AT, Newton RC, Olsen EJ, Wyllie PJ, Crewe AV, Isaacson MS, Johnson D (1970) Petrologic history of the moon inferred from petrography, mineralogy and petrogenesis of Apollo 11 rocks. In: Proceedings of the Apollo 11 Lunar Science Conference 1:897-925

Smyth JR, McCormick TC (1995) Crystallographic data for minerals. Miner Phys Crystallogr A Handb Phys Constants 2:1-7

Soret C (1880) Sur l'etat d'équilibre que prend au point de vue de sa concentration une dissolution saline primitivement homogène dont deux parties sont portées a des températures difféntes: Deuxieme note.

Stokes GG (1851) On the effect of the internal friction of fluids on the motion of pendulums. Trans Camb Philos Soc 9:8-106

Thy P, Lesher CE, Nielsen TF, Brooks CK (2006) Experimental constraints on the Skaergaard liquid line of descent. Lithos 92:154-180

Tomkins MR, Baldock TE, Nielsen P (2005) Hindered settling of sand grains. Sedimentology 52:1425-1432

Toplis MJ, Carroll MR (1995) An experimental study of the influence of oxygen fugacity on Fe-Ti oxide stability, phase relations, and mineral - melt equilibria in ferro-basaltic systems. J Pet 36:1137-1170

Tribaudino M, Angel RJ, Cámara F, Nestola F, Pasqual D, Margiolaki I (2010) Thermal expansion of plagioclase feldspars. Contrib Miner Pet 160:899-908

Trubowitz CA (2018) Quantifying water contents in silicate glasses using confocal Raman microspectoscopy. B.Sc. Thesis ETH Zurich, pp. 40

Turcotte D, Schubert G (2002) Geodynamics. Cambridge University Press

Vander Auwera J, Longhi J, Duchesne JC (1998) A liquid line of descent of the jotunite (hypersthene monzodiorite) suite. J Pet 39:439-468

Villiger S, Ulmer P, Müntener O (2007) Equilibrium and fractional crystallization experiments at $0.7 \mathrm{GPa}$; the effect of pressure on phase relations and liquid compositions. J Pet 48:159-184 
Wager LR, Brown GM (1968) Layered igneous rocks. Oliver \& Boyd, Edinburgh and London, p 588

Wager LR, Brown GM, Wadsworth WJ (1960) Types of igneous cumulates. J Petrol 1:73-85

Wainwright JE, Starkey J (1971) A refinement of the structure of anorthite. Z Kristallogr 133:75-84

Walker D, Hays JF (1977) Plagioclase floatation and lunar crust formation. Geology 5:425-428

Watson E, Wark D, Price J, Van Orman J (2002) Mapping the thermal structure of solid-media pressure assemblies. Contrib Miner Pet 142:640-652

Wilson AH (1982) The geology of the Great 'Dyke', Zimbabwe: the ultramafic rocks. J Pet 23:240-292

Wilson AH, Naldrett AJ, Tredoux M (1989) Distribution and controls of platinum group element and base metal mineralization in the
Darwendale subchamber of the Great Dyke, Zimbabwe. Geology 17:649-652

Wilson JR, Robins B, Nielsen FM, Duchesne JC, Vander Auwera J (1996) The Bjerkreim-Sokndal layered intrusion, Southwest Norway. Dev Pet 15:231-255

Winter JK, Okamura FP, Subrata G (1979) A high-temperature structural study of high albite, monalbite, and the analbite $\rightarrow$ monalbite phase transition. Am Miner 64:409-423

Publisher's Note Springer Nature remains neutral with regard to jurisdictional claims in published maps and institutional affiliations. 